\title{
Journal of Paleolimnology \\ Eutrophication erodes inter-basin variation in macrophytes and co-occurring invertebrates in a shallow lake: Combining ecology and palaeoecology --Manuscript Draft--
}

Manuscript Number:

Full Title:

Article Type:

Keywords:

Corresponding Author:
JOPL-D-16-00092R1

Eutrophication erodes inter-basin variation in macrophytes and co-occurring invertebrates in a shallow lake: Combining ecology and palaeoecology

\section{S.I. : Putting the ecology into palaeoecology}

Anthropogenic impact; Community heterogeneity; Historical dynamics; Light limitation; Lough Erne System; Multi-proxy study

Jorge Salgado, PhD

Universidad de Los Andes, Laboratorio de Palinología y Paleoecología Tropical, Departamento de Ciencias Biológicas. Carrera 1 No. 18A-12, Bogotá, Colombia Bogotá, COLOMBIA

\section{Corresponding Author Secondary} Information:

Corresponding Author's Institution:

Universidad de Los Andes, Laboratorio de Palinología y Paleoecología Tropical, Departamento de Ciencias Biológicas. Carrera 1 No. 18A-12, Bogotá, Colombia

Corresponding Author's Secondary Institution:

First Author:

Jorge Salgado, $\mathrm{PhD}$

First Author Secondary Information:

Order of Authors:

Jorge Salgado, PhD

Carl D. Sayer, PhD

Stephen J. Brooks, BA

Thomas A. Davidson, PhD

Beth Okamura, PhD

Order of Authors Secondary Information:

Funding Information:

Natural History Museum London

Dr. Jorge Salgado

Freshwater Biological Association

Dr. Jorge Salgado

$\mathrm{AU}$ ideas programme

Dr. Thomas A. Davidson

EU FP7 Project Biofresh (226874)

Colciencias

(Es tiempo de volver)

Dr. Jorge Salgado

Dr. Jorge Salgado

Aquatic biodiversity is commonly linked with environmental variation in lake networks, but less is known about how local factors may influence within-lake biological heterogeneity. Using a combined ecological and multi-proxy palaeoecological approach we investigated long-term changes in the pathways and processes that underlie eutrophication and water depth effects on lake macrophyte and invertebrate communities across three basins in a shallow lake - Castle Lough, Northern Ireland, UK. Contemporary data allow us to assess how macrophyte assemblages vary in composition and heterogeneity according to basin-specific factors (e.g. variation in water depth), while palaeoecological data (macrophytes and co-occurring invertebrates) enable us to infer basin-specific impacts and susceptibilities to nutrientenrichment. Results indicate that variability in water depth promotes assemblage variation amongst the lake basins, stimulating within-lake macrophyte assemblage heterogeneity and hence higher lake biodiversity. The palaeo-data indicate that eutrophication has acted as a strong homogenising agent of macrophyte and 
invertebrate diversities and abundances over time at the whole-lake scale. This novel finding strongly suggests that, as eutrophication advances, the influence of water depth on community heterogeneity is gradually eroded and that ultimately a limited set of eutrophication-tolerant species will become homogeneously distributed across the entire lake.

\section{Suggested Reviewers:}

\section{Response to Reviewers:}

Bent Vad Odgaard, PhD.

Professor, Aarhus Universitet

bvo@geo.au.dk

Professor Odgaard is a leading scientist in macrofossils and environmental change

Hillary H. Birks, PhD.

Professor, Universitetet i Bergen

Hilary.Birks@uib.no

Professor Birks is a leading scientist in the application of plant macrofossils to investigate the effects of environmental change on temperate ecosystems

We are pleased to submit our revised manuscript entitled "Eutrophication erodes interbasin variation in macrophytes and co-occurring invertebrates in a shallow lake:

Combining ecology and paleoecology".

We have gone through both Reviewer's and Guest Editor's comments with care and have made nearly all the suggested revisions (detailed responses below). We are confident that these helpful reviews have enabled us to improve our manuscript without changing the conclusions of our work.

We thank you, the Guest Editor (Dr. Thomas J. Whitmore) and our two Reviewers for taking the time to help us to improve our manuscript. If you have any questions please do not hesitate to contact me

Sincerely, Jorge Salgado, PhD.

General comment:

We have edited our manuscript to address most of the Reviewers' and the Editor's concerns. One point that was raised by both Reviewers and the Editor was that it was hard to follow the temporal reconstruction of eutrophication and water depth effects between basins. Thus, we have included a new analysis (Indval) to identify characteristic species at each selected time interval and basin, and have created a new summary Table (Table 2), which includes the selected species ecology in relation to water depth, eutrophication and macrophyte cover. We hope this makes things clearer.

Reviewer \#1:

Reviewer: This paper attempts to address the dynamics of changes in macrophyte assemblage from three distinct basins of Castle Lough, a shallow well-connected water body in 24 Northern Ireland, UK, by using the paleolimnological method to restore the historical changes of macrophyte assemblage and environmental factors such as water depth and nutrient loading. It is an interesting topic and the authors provide the potential to extend the ecological change record and dynamics analysis. I agree with the opinion of which the macrophyte distribution in space can help to explain the temporal change.

But I have a concern that the three basins have so much similarity and the spatial heterogeneity is not large enough to explain the historical changes (as the first three or four dominant macrophyte species are same in three basins in Fig. 2), while the environmental conditions are not different significantly, which will result in the homogeneity in macrophyte spatial distribution and abundance.

Response: The reviewer has not appreciated that our results and analyses have clearly identified a significant separation between basins in both macrophyte assemblages (variation in composition and relative abundance- PerManova analysis and HMD respectively) and water depth profiles (PerManova analysis, including differences in heterogeneity in water depths- HMD) (Figs. 2, ESM 2). Furthermore, our 
study uniquely demonstrates that heterogeneity between basins is not only determined by differences in species composition but also by variation in relative abundances between basins.

On a temporal scale, the separation between basins was further supported by NMDS plots of the palaeo-data (Figure 3), which similarly showed that over the last two centuries, macrophyte communities at basin 1 have differed from the other two basins. Temporal patterns in distributions of daphnid ephippia and selected chironomid taxa support further the idea that the basins have retained similar depth profiles over time (Discussion section, Lines: 410-421).

This collective evidence demonstrates that environmental conditions linked to water depth variation between basins have been sufficiently large over time to explain the current spatial patterns in macrophyte communities. The parallel changes in macrophyte assemblages between basins and the observed convergence to similar associations over time in ordinational space (Fig. 3) suggest however that other environmental conditions have changed over time and all the multiproxy evidence points towards a strong effect of eutrophication (Discussion section, Lines: 422-443).

Reviewer: I believe the water level is an important factor regulating the macrophyte assemblage, composition and abundance, but there are other factors which would affect the macrophyte assemblage, such as the sediment, wind fetch and intensity, solid suspension, ammonia nitrogen, etc. How much degree of these factors influence on the macrophyte assemblage?

Response: In the discussion we address the potential co-influence of other factors besides water depth, like exposure and sediment characteristics (Lines: 368-389). We have also added a new paragraph at the end of this section (lines 400-407 that outlines more generally the issue of identifying drivers of assemblage change.

Reviewer: In addition, the macrophyte-reminds in the sediment, the flux or abundance index, how much accuracy it can explain the historical changes of macrophyte assemblage?

Response: There is a supportive literature showing a good accuracy of plant macrofossils explaining contemporary and historical changes including Zhao et al. 2006; Davidson et al. 2005; Salgado et al. 2010; Madgewick et al. 2012; Clarke et al. 2016; Lhevi et al. 2016. For clarification, we have included a new paragraph in the discussion section addressing this issues (Lines: 489-507).

Reviewer: Finally, the environmental driving factors, water depth and trophic level should be rebuilt since pre-1900 and clearly showed in the paper. The linkage between the macrophyte assemblage changes and environmental condition changes was not tightly and clearly demonstrated in the text.

Response: Lines 410-460 in discussion are dedicated to demonstrate these changes. To clarify the patterns we have produced a new summary Table (Table 2) derived from a new analysis (Indval) to identify characteristic species at each selected time interval and basin. The table includes the selected species ecology in relation to water depth, eutrophication and associations with macrophytes over three time periods.

Reviewer \#2:

Reviewer: Comments on Salgado et al: Putting space into time: long-term shifts in the importance of water depth and eutrophication in structuring lake assemblages

This is an excellent paper taking forward the study of variation within a lake controlled largely by water depth and how the ecosystems within a lake have responded to eutrophication processes. Castle Lake is rather special in having three distinct basins. Perhaps a commentary on what happened over time in each basin would be useful, as the communities are different. These data are present in the paper, but are hard to isolate.

Response: Lines 423-502 in discussion are dedicated to demonstrate these changes and as outlined in our above response to Reviewer 1, we have now included our new summary Table 2 to clarify these changes.

Reviewer: Studies on simple lakes have shown how macrophyte distributions vary with water depth and with position in a lake. Surface-mud samples have shown how 
macrofossil remains reflect these different communities. However, there is not much historical or palaeo-evidence to indicate how these separate communities originated within a lake and how they have responded to an overall driver such as nutrient enrichment. Here is the next challenge for these authors.

Response: This is basically what we are addressing in this paper so we do not know how to address this comment. Perhaps the reviewer is simply stating that this is an important area for research.

Reviewer:

Title: I do not think 'Putting space into time' is very useful. It does not actually mean anything. Perhaps you could use something like - 'Tracking time in space' Response: We thank the reviewer for highlighting this issue. We have now changed the title to: "Eutrophication erodes inter-basin variation in macrophytes and cooccurring invertebrates in a shallow lake: Combining ecology and palaeoecology"

We have made several changes in the document, which might have affected these specific changes and line numbers might not correspond anymore. We tried however to address most comments.

Abstract

Line 19: Aquatic biodiversity commonly increases with environmental variation ..... Done- Line 23

Line 20: replace 'influences' by 'factors' and 'impact' with 'influence'

We changed most of the abstract structure so it does not apply anymore

Line 24: We surveyed assemblages to provide contemporary data on macrophyte distributions and abundances and acquired palaeoecological data

We changed most of the abstract structure so it does not apply anymore

Line 32: after 'all groups' insert 'in recent decades'

We changed most of the abstract structure so it does not apply anymore

Line 34: replace 'positive effects' with 'driving influence'

We changed most of the abstract structure so it does not pertain anymore

Introduction

Line 52: 'beavers' is not a good example; they have never occurred in Ireland in the Holocene. How about otters?

We eliminated the sentences to avoid any problem with specific taxa (Lines: 51-55)

Line 53: Such within-lake variation 'influences' spatial ...

Done-line 57

Line 79: after 'basins' add 'in a lake'

We edit the whole paragraph so it does not apply anymore

Palaeolimnological analyses

Line 124: you actually retrieved cores from the mid-points of the areas sampled for macrophytes (Fig. 1)

Amended- Lines 125-127

Line 140: delete ',' after 'included'

Done

Line 141: after 'seeds' add 'and fruits'

Done-Line 143

Line 146: Move the sentence starting with 'Macrofossils ..' up to line 141, after Isoetes megaspores. Then all the methods relating to macrophytes are together.

Response: Given that we selected macrofossils of different biological groups at the same time, we believed that it is better to have them all together as it is in the original manuscript. 
Line 153: what about 1951-1965? Why is this decade missing? On the diagrams in Figures 4-6 and Suppl figure S5 this period is covered as 1941-1955 and 1956-1965. Please can you explain this?

Response: This has been clarified with a new sentence in the method section (lines: 134-137). "Exceptions were two 15-year intervals (1940-1955 and 1965-1980) due to differential sedimentation rates (see results) between cores."

Line 158: you coded something with a presence of 1 as 0 . But it was present! So this is a misrepresentation of the data. I think you should use 1 or perhaps better, '+'.

Response: This concern pertains to the way we average the missing time period data (due to slower sedimentation rates) in NCAS2 core to establish decadal comparisons amongst the cores (Lines 154-161). We took a parsimonious approach and in the particular case were adjacent samples were 1 and 0 prefer to coded them as 0 . We believed that this is not a misinterpretation of the data as we really don't know if it's present, given that in the older sample is absent. Thus, we prefer to be cautious and not coding something present when there was not really evidence for that.

Reviewer: Historical spatial patterns: I like this! Often the H's are close and travel to P's which are also close. Basin 1 seems to be rather distinct from the other two, suggesting that water-depth is still the major environmental factor here, whereas the other shallower two are influenced more by nutrient enrichment.

Response: Basin 1 seems to be rather distinct from the other two as it is the shallowest of the three and the paleo-data suggest that his has been a common feature over the last two centuries. Thus, we believe that water depth is still a major environmental factor. Nonetheless, our paleo-data also shows that some biological changes attributed to eutrophication occurred early at basin 1 (e.g. the expansion of Myriophyllum) suggesting that all three basins have been influenced by nutrients over time (see Discussion section, Lines 469-480).

Line 335: replace Fig. $6 a$ with $6 \mathrm{~b}$

Amended

Discussion

Line 368: Add 'Fig. 2a' after '1970)'. Next sentence was rather unclear to me. Perhaps you mean Widespread cover by the water lily Nuphar lutea provides dense shade which reduces the abundances of more light-sensitive ..... Although N. lutea is abundant in your plots, its seeds are very rare (characteristic of N. lutea). You should mention that it is represented more realistically by the trichosclereid record, although this also includes Nymphaea alba (whose seeds are not quite so rare). Curiously, although its seeds are more common than N. lutea, N. alba does not seem to be recorded from the present vegetation (Fig 2a). Did you include its leaves with N. lutea? Response: We have amended the sentence and also have highlighted that was mostly represented by sclereids. Lines 373-377

Line 392: replace 'in' with 'at'

Done

Line 394: replace 'likely' with 'probably'

Done

Line 500: include Zhao et al. in the references

Done

Line 507: you should consider the essay by Birks HJB (2014), Vegetation History and Archaeobotany 23: 309-330

Response: This reference has been included in Line: 402

\section{Conclusions}

Line 525 onward: This conclusion is based on previous studies of eutrophic lakes Response: We have amended the whole conclusion section so probably does not pertain any more but still pur conclusion is based on our own results

Line 529: What do you mean by 'good condition'? This is an anthropogenic value judgement! Please clarify (e.g. it is mesotrophic with a high diversity of taxa) Amended- Line 550-551 
Line 531: rewrite: ... that the lake ecosystem is responding to increasing eutrophication and a homogenous assemblage ...

Amended

What is causing eutrophication of Castle Lake at present? Are and how are these factors predicted to increase in intensity in the future? How long do you think it will take for the ecosystems to become homogenous, given the known stressors and rates of change? Is there a conservation priority here? Some taxa are already extinct in parts of the lake (e.g. Najas flexilis) - others may follow?

Response: We have included a new paragraph in lines: 550-558

Line 534: replace 'illustrates' with 'adds to'. There are several other studies of eutrophication processes already.

Amended

Line 539: after 'impacts that' add 'affect the ecosystems in the individual basins at first, depending on their susceptibility to nutrient input. If the nutrient inputs continue, it is likely that the assemblages will become homogenous over the whole lake (see Donohue et al. 2009).'

Response: We have included a new paragraph in lines: 550-558

Figure 1

a. Distances are usually given in $\mathrm{km}$. The text is too small to read even with a magnifying glass!

c. - a distance scale is needed. The key should be labelled as 'water depth'

Amended

Editor comments:

1.Line 105: the possessive apostrophe can be removed from "1950's"

Amended

2. Line 115: Percent volume "infestation" is a term that has been used in some contexts, and although I studied and worked for a time with Canfield, I have much trouble with that term and would like to suggest an alternative. Infestation is an older management term that implies that all aquatic plants are problematic (Canfield formerly worked at the "Center for Aquatic Weeds" at University of Florida) and indeed many of the people associated with Canfield are plant-management chemical applicators. For an ecological perspective, as in the present study, perhaps it might be preferable to paraphrase your statement, such as "using the method of Canfield et al. (1984) to determine the percent of lake volume filled by macrophytes," and to avoid "infestation" or the usual acronym. (Sometimes I've described it as percent volume infilled.) In most instances, the space saved by an acronym is minimal in a publication, and writing things out makes it clearer for all readers. In this case, "infestation" and the acronym have unfortunate connotations that are not very ecologically oriented.

Amended in lines: 117-123

3. For appendices presented as Electronic Supplementary Material, please use an ESM numbering sequence, such as ESM1, ESM2, etc. rather than indicating the type of material and an $\mathrm{S}$ designation

Amended

4. Table 1 and in the text: if the intention is to demonstrate strength of relationships, wouldn't correlation coefficients [r] be more appropriate than coefficients of determination [r2]? R values demonstrate the strength of a relationship between variables, but $r 2$ values are used when the intention is to construct a predictive model and show the proportion of variation in the dependent variable explained by an independent variable, as you know and state elsewhere in the text. Perhaps I am missing a point here.

Response: We agree with the editor's concern but the original aim of the tests on space-time interactions developed by Legenedre et al. (2010) was indeed to construct a predictive model to show how much of the variation was explained by these two 
independent variables. Thus results are presented on R2 values. We similarly wanted to go further than just a demonstration of the strength of relationship between variables.

5. Figure 1 legend: please remove "see Methods for details", as the journal tends to discourage internal pointers

Amended

6. Line 149: please remove "e.g." from all citations for journal format needs Amended

7. Line 267-268: in this wording, you are explaining the proportion of variation based on GLM: should this read R2adj rather than Radj?

Amended

8. Reviewer 1 makes a good point about similarity of the basins, homogeneity, and the potential to minimize "other factors which would affect the macrophyte assemblage, such as the sediment, wind fetch and intensity, solid suspension, ammonia nitrogen, etc.". One useful thing that I did learn from Canfield pertained to "scale of analysis", which relates to the fact that a wide range of studies about relationships between macrophytes and environmental variables will demonstrate a wide range of conclusions about what the important factors are that most influence macrophyte communities. It might be helpful to address the reviewer's concern by mentioning that conclusions about important factors that influence macrophyte communities are often determined by the experimental design and local conditions, that is, when all other factors tend to be homogeneous, the factors that vary will assume apparent importance in explaining community differences. Readers might otherwise generalize to conclude that the important factors in one situation will prove most important in all other contexts.

Response: In the discussion we address the potential co-influence of other factors besides water depth, like exposure and sediment characteristics (Lines: 368-389). We have also added a new paragraph at the end of this section (lines 400-407 that outlines more generally the issue of identifying drivers of assemblage change.

Perhaps Reviewer 2 expresses similar concerns with this statement, but I must admit that the meaning is not entirely clear to me:

"Studies on simple lakes have shown how macrophyte distributions vary with water depth and with position in a lake. Surface-mud samples have shown how macrofossil remains reflect these different communities. However, there is not much historical or palaeo-evidence to indicate how these separate communities originated within a lake and how they have responded to an overall driver such as nutrient enrichment. Here is the next challenge for these authors."

Response: As we have indicated, we are also not entirely sure with this concern as it basically what we are trying to show.

9. Regarding Reviewer 1's second principal concern about "In addition, the macrophyte-reminds [sic] in the sediment, the flux or abundance index, how much accuracy it can explain the historical changes of macrophyte assemblage?" I think that can be addressed by describing findings from other studies by the authors. I note, for example, that Reviewer 2 recommends "include Zhao et al. in the references". Amended

10. Reviewer 1's concern "Finally, the environmental driving factors, water depth and trophic level should be rebuilt since pre-1900 and clearly showed in the paper" appears to be a helpful suggestion for a summary figure. Reviewer 2, as well, notes "Perhaps a commentary on what happened over time in each basin would be useful, as the communities are different. These data are present in the paper, but are hard to isolate." Response: Lines 411-461 in discussion are dedicated to demonstrate these changes. And, as pointed out above, we have provided a new summary table (Table 2) deriving from a new analysis (Indval) to identify characteristic species at each selected time interval and basin. The Table includes the selected species' ecologies in relation to water depth, eutrophication and associations with macrophytes over three time periods. 


\section{Eutrophication erodes inter-basin variation in macrophytes \\ 2 and co-occurring invertebrates in a shallow lake: Combining \\ 3 ecology and palaeoecology}

4

5 Jorge Salgado ${ }^{1,2,3}$, Carl D. Sayer ${ }^{2}$, Stephen J. Brooks ${ }^{1}$, Thomas A. Davidson ${ }^{4,5}$, and

6 Beth Okamura ${ }^{1}$

$7{ }^{1}$ Department of Life Sciences, Natural History Museum, Cromwell Road, London,

8 SW7 5BD, United Kingdom

$9 \quad{ }^{2}$ Environmental Change Research Centre, Department of Geography, University

10 College London, Gower Street, London. WC1E 6BT, United Kingdom.

$11{ }^{3}$ Current address: Laboratorio de Palinología y Paleoecología Tropical, Departamento

12 de Ciencias Biológicas, Universidad de Los Andes, Carrera Primera \# 18A - 12,

13 Bogotá, Colombia

$14{ }^{4}$ Lake Group, Department of Bioscience, Aarhus University, Silkeborg, Denmark

$15{ }^{5}$ Section for ecoinformatics and biodiversity, Department of Bioscience, Aarhus,

16 Denmark

17 Corresponding author: Jorge Salgado, j.salgado@ uniandes.edu.co, Tel: +57 (1)

183394949 ext. 2729, Fax: 57 (1) 3394949. Departamento de Ciencias Biológicas,

19 Universidad de Los Andes, Carrera Primera \# 18A - 12, Bogotá, Colombia

20 Keywords: Anthropogenic impact; Community heterogeneity; Historical dynamics;

21 Light limitation; Lough Erne System; Multi-proxy study; 
23 Aquatic biodiversity is commonly linked with environmental variation in lake

24 networks, but less is known about how local factors may influence within-lake

25 biological heterogeneity. Using a combined ecological and multi-proxy

26 palaeoecological approach we investigated long-term changes in the pathways and

27 processes that underlie eutrophication and water depth effects on lake macrophyte and

28 invertebrate communities across three basins in a shallow lake - Castle Lough,

29 Northern Ireland, UK. Contemporary data allow us to assess how macrophyte

30 assemblages vary in composition and heterogeneity according to basin-specific

31 factors (e.g. variation in water depth), while palaeoecological data (macrophytes and

32 co-occurring invertebrates) enable us to infer basin-specific impacts and

33 susceptibilities to nutrient-enrichment. Results indicate that variability in water depth

34 promotes assemblage variation amongst the lake basins, stimulating within-lake

35 macrophyte assemblage heterogeneity and hence higher lake biodiversity. The palaeo-

36 data indicate that eutrophication has acted as a strong homogenising agent of

37 macrophyte and invertebrate diversities and abundances over time at the whole-lake

38 scale. This novel finding strongly suggests that, as eutrophication advances, the

39 influence of water depth on community heterogeneity is gradually eroded and that

40 ultimately a limited set of eutrophication-tolerant species will become homogeneously

41 distributed across the entire lake. 


\section{Introduction}

Lakes have been regarded as ideal models for studying the influence of local environmental effects on species turnover in systems that are interconnected at the landscape level (Leibold and Norberg 2004). The structuring influence of environmental factors on within-lake spatial variation in community composition has, however, received less attention although such an idea is acknowledged theoretically by the "submetacommunity concept" of Leibold and Norberg (2004). This oversight may reflect the fact that research has largely focused on populations of mobile planktonic organisms assumed to be well-mixed within lakes. Lake environmental heterogeneity may, however, be important in influencing the distributions and abundances of taxa with limited mobility. Local distributions of aquatic macrophytes, for example, may depend on competition for space and tolerance to local environmental conditions (Barrat-Segretain 1996). Moreover, different areas within lakes may vary substantially, for example, in water depth, sediment type, wind exposure, proximity to inflows/outflows and the presence of shoreline vegetation. Such within-lake variation influences the spatial distribution of aquatic vegetation (Spence 1967; Carpenter and Titus 1984) and, in turn, associated invertebrates due to local variation in habitat, structural complexity and feeding opportunities (Lauridsen et al. 1996).

Studies of biological assembly dynamics in lake systems are generally limited to snapshots in time, focusing on short-term or contemporary patterns of species turnover or on biogeographical patterns. The interplay between spatial distributions and environmental drivers may, however, shift locally over time (Korhonen et al. 2010). Indeed, increasing evidence that colonisation histories, priority effects and temporal changes in environmental variables influence both local and regional species distributions highlights the importance of studying species turnover (beta-diversity) within lakes over time (Fukami and Morin 2003). For instance, contemporary and palaeolimnological studies of Daphnia colonisation patterns revealed that assembly history initially influenced species composition, but that changes in water temperature and lake stratification subsequently drove species turnover (Allen et al. 2011). Furthermore, species-specific differences in colonisation and adaptive capacity have 
73 been shown to substantially influence temporal beta-diversity and to obscure direct

74 relationships between Daphnia species distributions and environmental gradients

75 (Urban and De Meester 2009). Palaeolimnological studies have also demonstrated

76 that changes in the nature and intensity of local factors can influence distributions and

77 abundances over time. For example, drivers of macrophyte assembly change were

78 shown to shift from lake in-filling during most of the Holocene to eutrophication

79 around 120 years ago (Rasmussen and Anderson 2005).

80

By utilising a combined ecological and multi-proxy palaeoecological

81 approach, this study aims to understand how key long-term environmental drivers (i.e.

82 shallowing and nutrient-enrichment) influence temporal variation in the distribution

83 of lake macrophytes and associated invertebrate assemblages across three basins of

84 Castle Lough, a shallow lake in Northern Ireland, UK. Our study evaluates the

85 hypothesis that variation in macrophyte and co-occurring invertebrate assemblages is

86 reduced over time due to the homogenising influence of eutrophication.

87

Study system

89 Castle Lough is a small (surface area $=13$ ha.), shallow (5 m maximum depth),

90 lowland (45 $\mathrm{m}$ above sea level) lake located in the south of the Upper Lough Erne

91 (ULE) system, a highly connected shallow lake network in Co. Fermanagh, Northern

92 Ireland $\left(54^{\circ} 12^{\prime} \mathrm{N}, 007^{\circ} 37^{\prime} \mathrm{W}\right)$. The lake has three distinct basins and moderate annual

93 mean total phosphorus $\left(29 \mu \mathrm{g} \mathrm{TP} \mathrm{L}^{-1}\right)$ and total nitrogen $\left(1.03 \mathrm{mg} \mathrm{TN} \mathrm{L}^{-1}\right)$

94 concentrations. The River Finn connects the lake to the main ULE system (Fig. 1),

95 which consists of a large "mother" lake and several linked satellite lakes.

Over the last 120 years hydrological change and eutrophication have

97 profoundly influenced the ecology of the ULE system (Battarbee 1986; Gibson et al.

98 1995). Frequent flood events in the catchment caused by high rainfall led to the

99 development of a major drainage scheme between 1880-1890 (Price 1890). Because

100 of this scheme, water levels in the main lake dropped from around 46 to $44 \mathrm{~m}$ above 
101 sea level (Price 1890). A second attempt to regulate water levels (dredging of $30 \mathrm{~km}$ 102 of channel between the ULE and Lower Lough Erne systems) was undertaken in the 103 early 1950s under the Erne Drainage and Development Act (Northern Ireland). Water 104 levels have subsequently been maintained between $43-45 \mathrm{~m}$, but the system (including 105 Castle Lough) is still prone to major flood events (Mathers et al. 2002). Diatom-based 106 palaeolimnological studies indicate a gradual acceleration of nutrient-enrichment in 107 the ULE since the 1900s with a major phase of eutrophication after c. 1950 (Battarbee 108 1986; Gibson et al. 1995).

109

\section{Materials and methods}

Contemporary macrophyte surveys

112 To characterize present-day distributions and abundances of macrophytes in Castle

113 Lough, we sampled three circular areas of $30 \mathrm{~m}$ radius in each of the lake's three main 114 basins (Fig. 1) (Table 1). To ensure broad and equivalent sampling, each area was 115 divided into three sub-areas delimited by $10 \mathrm{~m}$ radii (Fig. 1b). Six points were 116 surveyed from the innermost area, and 18 and 36 points for the successively larger 117 sub-areas, respectively (total $=60$ points). We used the method of Canfield et al. 118 (1984) to determine the percentage of lake volume filled by macrophytes (PVI) at 119 each point. This entailed surveying macrophytes from a boat using a combination of 120 grapnel sampling and visual observations made with a bathyscope. At each point 121 water depth, average plant height and species percentage cover were recorded for an 122 estimated area of $1 \mathrm{~m}^{2}$. For each sampling point, PVI was calculated as: (macrophyte $123 \%$ cover $\mathrm{x}$ average height of macrophyte)/water depth. 
Palaeolimnological analyses

124

125 We retrieved three sediment cores (NCAS1, NCAS2 and NCAS3) from the midpoint

126 of each of the sampling circular areas in each basin in June 2008 (Fig. 1b) using a

127 wide-bore (14 cm) "Big-Ben" piston corer (Patmore et al. 2014). Cores NCAS1,

128 NCAS2 and NCAS3 were collected from water depths of $117 \mathrm{~cm}, 180 \mathrm{~cm}$ and 160

$129 \mathrm{~cm}$, respectively, and were extruded in the field at 1-cm intervals. Lithostratigraphic

130 changes in the cores were recorded in the field. Core chronologies were determined

131 using ${ }^{210} \mathrm{~Pb}$ gamma counting (Appleby et al. 1986) at the Bloomsbury Environmental

132 Isotope Facility (BEIF), University College London (UCL). Dates were ascribed

133 using the Constant Rate of Supply (CRS) model (Appleby and Oldfield, 1978).

134 Eleven 1-cm slices were analysed for macrofossils from each core at a

135 resolution of $c .10$-year intervals, spanning the last $c .110$ years. Exceptions were two

136 15-year intervals (1940-1955 and 1965-1980) due to differential sedimentation rates

137 (see results) between cores. Macrofossil analyses were performed using an adaptation

138 of standard methods (Birks 2001). We analysed approximately $70 \mathrm{~cm}^{3}$ of sediment

139 and all samples were disaggregated in $10 \%$ potassium hydroxide $(\mathrm{KOH})$ before

140 sieving. Three sieves of mesh sizes $355 \mu \mathrm{m}, 125 \mu \mathrm{m}$ and $90 \mu \mathrm{m}$ were used to separate

141 plant, chironomid and other invertebrate remains. Given the high fossil retent on the

$142125 \mu \mathrm{m}$ and $90 \mu \mathrm{m}$ sieves, we combined and mixed both samples after sieving, and

143 analysed a 20-mL subsample. Plant macrofossils included seeds and fruits, leaf-

144 spines, leaf fragments (including water lilies leaf tissue- sclereids), charophyte

145 oospores and Isoetes megaspores. Invertebrate macrofossils included bryozoan

146 statoblasts (counted as valves), daphnid ephippia, molluscs (counts of whole shells,

147 half shells, opercula, shell fragments and glochidia larvae), and chironomid head

148 capsules. Chironomids were prepared for analysis using standard methods (Brooks et

149 al. 2007). Plant and animal macrofossil data were standardised as the number of

150 fossils per $100 \mathrm{~cm}^{3}$ and identified by comparison with reference material held at the

151 Environmental Change Research Centre (ECRC), UCL and the Natural History 
152 Museum, London, and by using relevant taxonomic keys (Aldridge and Horne 1998;

153 Birks 2001; Wood and Okamura 2005)

154 Given lower sedimentation rates for core NCAS2 (ESM1) and to establish

155 decadal comparisons amongst the cores, we combined the macrofossil data for three 156 time periods, 1941-1950, 1966-1980 and 1981-1990 for NCAS2. We used mean 157 macrofossil abundances between adjacent sediment samples for each given time 158 period. To avoid overestimating abundance values for the time intervals, we took a 159 parsimonious approach and rounded values to the lowest adjacent number. For 160 example, if adjacent sample values were 1 and 2 we gave a score of 1 for the sample 161 average. If it was 1 and 0 we coded with 0 and so on.

162

Data analysis

163

Contemporary environmental factors and macrophyte spatial distributions

165 As a measure of current lake environmental variation, we used the water depths 166 derived from the PVI data for each macrophyte sampling point. Similarly, we used 167 macrophyte percentage cover (for each sampling point) to characterise spatial 168 distributions and abundances of plant species in the three basins. Relationships 169 between macrophyte percentage frequencies and variation in water depth at the 170 whole-lake and basin levels were analysed using generalized linear models (GLM), 171 permutational analysis of multivariate dispersions (perMANOVA; Anderson 2001) 172 and homogeneity multivariate dispersion analysis (HMD; Anderson 2006). Whole173 lake scale analysis was assessed through a global GLM on all basin macrophyte 174 frequencies and water depths. Adjusted goodness of fit $\left(\mathrm{R}^{2}\right)$ and Akaike Information 175 Criteria (AIC) were used as GLM quality indicators. We evaluated the dispersion 176 parameter phi (Residual deviance (full model)/ residual degrees of freedom) to assess 177 any over-dispersion in the data and applied a negative binomial distribution if 
necessary (i.e. phi >1). Lastly, logistic regression using presence/absence as a response (with a binomial error distribution) was applied to evaluate the probability of finding key environmentally sensitive macrophyte species that are commonly lost following eutrophication across the observed depth profiles. Those macrophyte species highly vulnerable to eutrophication-induced declines were selected according to Madgwick et al. (2011). The explained percentage of macrophyte assemblage variation was corrected following Peres-Neto et al. (2006) and expressed as $\mathrm{R}^{2}$ adjusted.

HMD and perMANOVA were applied to assess independent variation in macrophyte assemblages and water depth profiles amongst the three basins. perMANOVA compares variability of dissimilarity distances within groups versus variability between groups, while HMD comprises a distance-based test of the homogeneity of multivariate dispersions between groups to their group centroid (Anderson 2006). Macrophyte species dissimilarities were calculated using the BrayCurtis dissimilarity index and water depth dissimilarities using Euclidean distances. Each basin was treated as independent (Anderson 2006). Using this approach, a basin having high multivariate dispersion (high values of dissimilarities and/or mean distance to group centroid) would be associated with large dissimilarities between macrophyte species or water depth and thus high heterogeneity (Anderson et al. 2006). The significance of the analyses was assessed by ANOVA $(P<0.05)$. A significant result indicates high variation between basins, while a lack of significance denotes no variation in macrophyte assemblage or depth variation between basins (Anderson et al. 2006).

To visualise how plant assemblage and depth variation were related across the three basins, we used NMDS on Bray-Curtis dissimilarities for the PVI data (which combines plant percentage cover and water depth into one measure). Of many potential measures of dissimilarity, Bray-Curtis has been shown to have one of the strongest relationships between site dissimilarity and ecological distance, hence providing optimum ordination results for the NMDS technique (Faith et al. 1987). 
Spatial and temporal dynamics of plant and invertebrate macrofossils

208

209 To quantify change over time in the spatial distributions of plant and invertebrate

210 macrofossils (henceforth referred to as space-time interaction), we applied an

211 ANOVA space-time test analysis (Legendre et al. 2010). We used "Model 5" of

212 Legendre et al. (2010), which uses principal coordinates of neighbour matrices

213 (PCNM) variables to assess the interaction between space and time, and Helmert 214 contrasts, also called "orthogonal dummy variables", to reconstruct a predictive 215 model assessing the independent effects of space and time.

To facilitate comparisons between cores, macrofossil data were expressed as fluxes. As plant macro-remains include a variety of differentially produced plant structures (e.g. spines, leaves and seeds), making realistic comparisons of taxon abundances is notoriously challenging (Birks 2001). Consequently, similar to the approach of Odgaard and Rasmussen (2001), we transformed each macrofossil flux record into a $0-5$ abundance scale, where 0 is absent and 5 is highly abundant, as follows: (i) we merged macrofossil fluxes from all three cores into a single matrix and ordered each taxon flux record from highest to lowest values; (ii) flux data were then transformed into percentage frequencies by assuming $100 \%$ for the highest flux value for each taxon; (iii) percentage frequencies were clustered using a DAFOR (Dominant, Abundant, Frequent, Occasional, Rare) scale as follows: 5 (100\%-80\%); 4 (79\%-60\%); 3 (59\%-40\%); 2 (39\%-20\%); 1 (19\%-1\%). Macrophyte DAFOR data were Hellinger transformed, while bryozoan, chironomid, mollusc and daphnid fluxes were first log-transformed and then Hellinger-transformed prior to ANOVA spacetime analyses. Each taxon group was tested independently and we constructed a siteby-taxon response data table with three-row blocks corresponding to a spatial and temporal location (i.e. basin 1, basin 2 and basin 3 at time $i$ ). We divided the macrofossil abundance data of each lake basin into 11 time-periods (a total of 33 data points) as follow: c. pre-1900; 1901-1910; 1911-1920; 1921-1930; 1931-1940; 1941$1950 ; 1955-1965 ; 1966-1980 ; 1981-1990 ; 1991-2000$ and 2001-2008. To assess the significance of each taxon group space-time interactions we used a significance of 
2370.05 and 999 permutations. Multidimensional scaling (NMDS) (Bray-Curtis metric)

238 was used to visualize trends in assemblage variation in space and time and K-means

239 partitioning analysis to detect significant changes in assemblage composition over

240 time ("cascadeKM" function of the "vegan" Package in R). The simple structure

241 index (ssi) was used to identify the best partition. To summarise the main temporal

242 changes in assemblage composition in relation to environmental driving factors, we

243 identified characteristic species for each time-period using the IndVal method

244 ("indval" function of the "labdsv", Package in R) of Dufrene and Legendre (1997).

245 For simplification purposes, we divided the palaeo-record of each biological group

246 into three synchronous time intervals of assemblage variation detected by K-means

247 across the five groups (see ESM4). These three time intervals were: pre-1900-1940,

248 1941-1980, and 1981-present.

249

\section{Results}

250

Contemporary macrophyte spatial patterns

252 Fourteen macrophyte species were recorded among the three basins (Fig. 2a). Elodea

253 canadensis Michx., Nuphar lutea (L.) Sm. Sagittaria sagittifolia L., and Sparganium

254 emersum Rehmann were the most abundant species, occurring in all three basins.

255 Filamentous algae (undifferentiated), Lemna trisulca L., Nitella flexilis L., and

256 Utricularia vulgaris L., were also recorded in all basins but at lower percentage cover.

257 Chara globularis J.L.Thuiller, Potamogeton obtusifolius Mert. \& W.D.J. Koch, and

258 Stratiotes aloides L. were present in basins 1 and 3 only, Potamogeton praelongus

259 Wulfen. was absent in basin 1, Callitriche sp. and Equisetum fluviatile L. were absent

260 in basins 1 and 3, and Myriophyllum verticillatum L. was absent in basins 2 and 3.

261 Filamentous algae occurred in all three basins and were more abundant in basins 2

262 and 3. 
Basin 1 was characterised by homogeneous shallow water depths (mean 116.7

$264 \pm 6.43 \mathrm{~cm}$ ), basin 2 by more heterogeneous and deeper waters (mean $164.7 \pm .28 .01$

$265 \mathrm{~cm}$ ) and basin 3 by homogenous deeper waters (mean 152.1 $\pm 3.5 \mathrm{~cm}$ ) (ESM2a).

266 Negative binomial GLM on macrophyte species percentage cover and water depth

267 values showed that water depth explained a highly significant $\left(P<0.0001 ; \mathrm{R}^{2}{ }_{\text {adj }}=30 \%\right)$

268 proportion of the variation in macrophyte assemblages at the whole-lake scale (Fig.

269 2b). A marked decline in macrophyte percentage cover was observed above a depth of $270160 \mathrm{~cm}$. Logistic regressions indicated that M. verticillatum, C. globularis, and $S$.

271 aloides were highly restricted $(\mathrm{P}<0.001$ in all cases) by water depth (ESM3) with 272 probability of occurrences greatly declining above $115-120 \mathrm{~cm}$. P. praelongus and $P$. 273 obtusifolius occurrences were similarly limited to depths between 115-160 cm but 274 with no statistically significant trend.

Multivariate analysis revealed substantial spatial variation in macrophyte assemblages and water depths between the three basins $(P=0.001$ in all perMANOVA and HMD cases) (ESM2b). HMD analysis revealed that macrophyte assemblage and water depth profiles in basin 2 were significantly more heterogeneous than in the other two basins (ESMS2c). The NMDS plot of PVI values showed a separation

280 between macrophyte Bray-Curtis dissimilarities of basin 1 (groups on the left-hand 281 side of the plot) and the other two basins (Fig. 3a). Bray-Curtis macrophyte dissimilarities of basins 2 and 3 overlapped in some cases.

Historical spatial patterns

285 Plant and invertebrate macrofossils were detected throughout the cores from each 286 basin (Figs. 4-6). ${ }^{210} \mathrm{~Pb}$-based radiometric chronologies and sedimentation rates for cores NCAS1, NCAS2 and NCAS3 are given in ESM1.

NMDS plots of all five taxonomic groups revealed a greater dissimilarity between basin 1 assemblages and the other two sampling basins over time (Fig. 3 be). The ANOVA space-time analysis of plant macrofossil abundances revealed a 
291 highly significant space-time interaction $(P=0.001)$ that explained $27 \%$ of assemblage

292 variation (Table 1$)$. The analysis also revealed a significant $(P=0.001)$ space-time

293 interaction for chironomids and molluscs, accounting for $32 \%$ and $29 \%$ of total

294 assemblage variation, respectively (Table 1).

Multivariate trajectory and K-means analyses revealed three significant time intervals (ESM4a) in which plant macrofossil composition differed significantly across the three basins (Fig. 4). These corresponded to $c$. pre-1900-1930, 1931-1980 and 1981-present. The initial changes are mostly attributed to early reductions in bryophytes (including Sphagnum spp. leaf remains), Najas flexilis (Willd.) Rost and Schmidt. seeds, Isoetes lacustris L. megaspores and S. aloides leaf-spines (Fig. 4, Table 2). Myriophyllum spp. leaves and seeds were present at high abundances (in particular in basin 1) along with P. praelongus/lucens (basins 2 and 3) during the 1930-1980s. After 1981 Nitella sp. oospores increased in basin 1 and remains of floating-leaved taxa such as L. trisulca, Nymphaeaceae and Sparganium sp. increased in all basins (Fig. 4, Table 2).

For chironomids, multivariate trajectory and K-means analyses revealed five main time intervals (ESM4b) in which assemblages differed significantly corresponding to $c$. pre-1900-1910, 1911-1940, 1941-1955, 1956-1980 and 19812008 (Fig. 5). At $c$. pre-1900-1920 differences are mostly attributed to prevalence in basin 3 of Ablabesmyia spp., Cryptochironomus spp., Cladotanytarsus mancus, Dicrotendipes nervosus, Pseudochironomus spp., Tanytarsus lugens, Tanytarsus pallidicornis, Stempellina spp., Stilocladius and the diamesine Protanypus sp. (Fig. 5, Table 2). The second-time interval (1921-1940) was associated with a reduction or disappearance of most of these taxa in basin 3, the appearance in subsequent time interval (1941-1955) of Glyptotendipes pallens and, especially in basin 1, of $D$. nervosus, Endochironomus albipennis, Cricotopus intersectus, Cricotopus laricomalis and Psectrocladius sordidellus. After 1956 (the fourth-time interval), Procladius spp. increased in abundance, especially in basin 2, together with a general increase in numbers of E. albipennis (basins 1 and 2), and of both G. pallens and Polypedilum sordens. From 1981 to present most of these taxa generally increased in abundance and were similarly distributed across the three basins (Fig. 5, Table 2). 
Multivariate trajectory and K-means analyses identified three time intervals in which mollusc assemblages differed significantly (ESM4c) - c pre-1900-1920, 19211950 and 1951-present. In the two earlier time intervals, most of the current taxa were absent and gastropods and the bivalves Pisidium spp. and Anodonta cignea L. (which produces glochidia larvae) occurred in very low abundances. Mollusc abundances showed a general increase in the 1950s (Fig. 6a, Table 2). The invasive bivalve, Dreissena polymorpha Pallas, first appeared in the 1990s consistent with its known recent arrival in the ULE system (Rosell et al. 1998).

No space-time interaction was revealed in the analyses of bryozoan statoblasts and daphnid ephippia (Table 1). Independent tests on the spatial factor confirmed, however, that both bryozoan and daphnid remains were strongly spatially structured over time ( $P=0.001$ for both cases) (Table 1). Spatial patterns explained $64 \%$ of assemblage variation for bryozoans and $41 \%$ for daphnids. For bryozoans, Plumatella spp. were generally absent in basin 1 and Plumatella fruticosa Allman was abundant in basin 3 (Fig. 6b, Table 2). Likewise, Ceriodaphnia spp. occurred abundantly throughout basin 1, while Daphnia spp. dominated in basins 2 and 3 (Fig. 6c, Table 2). For bryozoans, K-means analysis detected four time intervals in which assemblages differed significantly (ESM4d) at $c$. pre-1900-1940, 1941-1955, 19561980 and 1981-present. These temporal changes occurred mostly in basins 2 and 3, where the first-time interval was typified by dominance of $P$. fruticos $a$ in basin 3. At the second-time interval (1941-1955), P. fruticosa abundances declined while Plumatella spp., increased. The third-time period (1956-1980) was characterised by an increase in C. mucedo and Plumatella spp. as was the final post-1981 interval (Fig. 6b, Table 2). K-means analysis for daphnid ephippia resulted in three time intervals in which assemblages differed significantly (ESM4e) at $c$. pre-1900-1955, 1956-1990 and 1991-present. The first early time interval was typified by dominance of Ceriodaphnia spp. (basin 1), followed by a second-time period characterized by increases in Daphnia spp. and minor reductions in Ceriodaphnia spp. (Fig. 6c, Table 2). The final time period was characterised by an increase in Daphnia spp. and Ceriodaphnia spp. in basins 2 and 3. 

revealed three relatively synchronous time intervals of assemblage variation across

354 the five groups (ESM4) at pre-1900s-1940, 1941-1980, and 1981-1990. The first early

355 time interval corresponded with synchronous changes in plant, chironomid and 356 bryozoan remains, whereas synchronous changes characterised all five groups during 357 the second and most recent time intervals.

358

\section{Discussion}

\section{Contemporary distributions of macrophytes}

360 Our analyses have revealed significant spatial heterogeneity in macrophyte

361 assemblages across the three basins. Despite a general prevalence of the same three or 362 four species, the results highlighted macrophyte heterogeneity across basins both in 363 terms of species turnover and variation in species relative abundances. Furthermore,

364 our data revealed associations between macrophyte assemblage variation and 365 heterogeneity in water-depth (ESM1). This indicates that intra-basin variation may 366 also create other complex, non-linear effects on macrophyte spatial patterns (e.g. 367 greater niche availability with different depth profiles) (Anderson et al. 2006).

The detected strong relationship between water depth and spatial variation in 369 macrophyte community structure likely reflects light limitation. This is supported by 370 the peaty-brown colour of Castle Lough water and a general prevalence of 371 macrophyte species with floating leaves (e.g. water lilies, S. emersum and $S$. 372 sagittifolia) and high shade tolerance (e.g. E. canadensis) (Spence and Chrystal 1970; 373 Fig. 2a). A widespread shading effect by water lilies (N. lutea and N. alba-both 374 recently growing in the lake and greatly represented by sclereids in the paleo-data) 375 likely also contributes to reducing the abundances of other submerged species such as 376 M. verticillatum, U. vulgaris and C. globularis in the contemporary lake (Sculthorpe 377 1967). Other correlated abiotic factors may also influence macrophyte distributions. 378 For example, basin 1 is relatively well protected by reedswamp and floating-leaved 
379 species, while basins 2 and 3 are more exposed to wind and wave action (Fig. 1).

380 Exposure may reduce plant stands through fragmentation and uprooting (especially in

381 soft organic-rich sediments) and prevent the establishment of M. verticillatum, broad-

382 leaved species (e.g. P. praelongus and P. lucens; Barko and Smart 1986; Riis et al.

383 2001) and short and/or non-rooted species (e.g. S. aloides; Smolders et al. 2003),

384 which require sheltered habitats, a pattern consistent with our data (Fig. 2a). Increased

385 sediment transport with wave-movement can also influence propagule transport and

386 bury established plant stands (Keddy and Reznicek 1986). Differences in nutrient

387 concentrations between basins due to differential external loadings (e.g. proximity to

388 inflow (basin 1), pine woodland (basin 2), and the outflow (basin 3)) are also potential

389 co-associated factors influencing macrophyte spatial distributions (Carpenter and

390 Titus 1984).

391 In conjunction with water depth, plant seasonality and dispersal may also

392 contribute to macrophyte spatial distributions (Carpenter and Titus 1984, Sayer et al.

393 2010a). However, a strong concordance of our palaeo-data with observed macrophyte

394 spatial patterns suggests that the latter are informative, robust and not unduly

395 influenced by seasonality (Figs. 2a, 5). In contrast to the restricted and patchy

396 distributions of $C$. globularis, $M$. verticillatum, and $P$. praelongus in the present-day,

397 the palaeo-data indicate that these species were present across the whole lake in the

398 past. It can be inferred, therefore, that dispersal is probably sufficient to enable all

399 species to reach all lake basins, but species sorting has occurred over time linked to

400 between-basin variation in environmental forcing (Leibold et al. 2004).

401 The above considerations demonstrate that there may well be other drivers of

402 macrophyte assemblage structure in Castle Lough besides water depth that we did not

403 specifically measure. These drivers may act at similar or dissimilar spatial scales and

404 may also vary over time (see below). In general, the detection of various drivers of

405 assemblage structure will be dependent on experimental design, the measurement of

406 relevant conditions at appropriate scales and times, the ability to conduct statistical

407 analyses focusing on measured drivers, and identifying or discounting other potential

408 drivers by evidence-based argument. 
Drivers of temporal changes in community assembly

411 The palaeo-record suggests that the basins have retained similar depth profiles over 412 time. Temporal patterns in distributions of daphnid ephippia support this inference.

413 For example, Ceriodaphnia species are commonly reported to prefer macrophyte-

414 covered shallow waters (Lauridsen et al. 1996) and were mostly found in basin 1, the 415 shallowest basin (Fig. 6c, Table 2). On the other hand, some Daphnia species prefer 416 non-macrophyte dominated open water (Lauridsen and Lodge 1996; Davidson et al. 417 2010) and occurred throughout time in greater abundances in the less vegetated 418 deeper waters offered by basins 2 and 3 (Fig. 6c, Table 2). Similarly, the profundal419 associated chironomid taxa Microchironomous spp. and C. anthracinus exhibited 420 greatest abundances in basins 2 and 3 (Fig. 5, Table 2). These strong inter-basin 421 differences suggest that as in the current day, water depth variation has been an 422 important long-term driver of spatial ecology in Castle Lough.

423 Significant space-time interactions for macrophyte, chironomid and mollusc 424 assemblages and differing temporal trends in bryozoan and daphnid assemblages 425 between basins, suggest that the distributions of these groups have been modified 426 across basins over time in response to conditions unrelated to water depth. The 427 synchronous temporal changes in assemblages of all five groups (ESM4) and species 428 characteristic of each time-interval (detected by the IndVal analysis; Table 2), suggest 429 compositional changes reflecting a previously inferred acceleration of eutrophication 430 after around 1900 (Battarbee 1986). Before 1930, the lake was characterised by taxa 431 associated with low to intermediate nutrient conditions including the macrophytes $N$. 432 flexilis, I. lacustris, and bryophytes (Carpenter and Titus 1984; Sand-Jensen et al. 433 2008), the chironomids Stempellina spp., Pseudochironomus spp., Orthocladius 434 consobrinus and Protanypus spp. (Pinder and Reiss 1983; Brodersen and Lindegaard 435 1999) and the bryozoan P. fruticosa (Økland and Økland 2002) (Table 2). Post-1930 436 macrophytes converged spatially towards communities associated with mesotrophic437 eutrophic conditions, exemplified by increased abundances of Myriophyllum spp. and 
438

439 floating-leaved taxa (L. trisulca, water-lilies and Sparganium sp.), declines in the 440 macrophytes I. lacustris and N. flexilis, increases in Plumatella spp. (Hartikainen et 441 al. 2009) and concomitant reductions in chironomids intolerant of nutrient-rich 442 conditions (e.g. Stempellina spp., Pseudochironomus spp., O. consobrinus and 443 Protanypus spp.) in recent times (post 1981) collectively suggest further development 444 of eutrophication and its effects (Table 2).

446 assemblages since 1931 are to a large extent linked to those of macrophytes (Table 2).

447 Indeed, many chironomids depend on macrophytes for food, with some (e.g.

448 Microtendipes and Polypedilum species) feeding on epiphytic algae (Moller Pillot 449 2009), and others relying on living (e.g. Cricotopus species) or decomposing (e.g. 450 Stenochironomus species) plants as a source of food or substratum (Vallenduuk and 451 Moller Pillot 2007; Moller Pillot 2013). Direct associations between macrophyte and 452 chironomid abundances have been demonstrated previously in both contemporary 453 (Langdon et al. 2010) and palaeolimnological studies (Brodersen et al. 2001). Our 454 analysis suggests a particularly close association between Myriophyllum spp. and the 455 majority of Cricotopus morphotypes in basin 1 (Figs. 4, 5), perhaps reflecting the 456 large surface area provided by finely dissected Myriophyllum leaves that can in turn 457 support dense epiphytic algal communities (Sculthorpe 1967). Similarly, post 1981 458 increases abundances of chironomids (E. albipennis, G. barbipes and $P$. 459 nubeculosum) and molluscs (Pisidium spp. and snails) coincident with the expansion 460 of floating-leaved plant taxa (e.g. water lilies) could reflect increased availability of 461 epiphytic food (Sculthorpe 1967) (Table 2). It should be noted that K-means analysis did not detect the apparently close 463 links between macrophyte and invertebrate abundances after the early stages of 464 eutrophication in the 1930s as described above. Instead, K-means analysis indicated 465 that macrophyte assemblage variation remained stable until the 1980s, while 466 invertebrate assemblages varied in keeping with a proposed acceleration of nutrient467 enrichment in ULE after 1955 (Battarbee 1986). This apparent temporal disparity 468 between macrophyte and invertebrate dynamics could be attributed to a lack of 
469 statistical power in the macrophyte data (Legendre et al. 2010). Between 1955-1980, there were indeed strong increases in abundances of Myriophyllum spp. and of the chironomid Cricotopus spp. but mainly in core NCAS1 (basin 1) (Figs. 4, 5). This suggests that an important phase of change probably occurred earlier and was undetected in the study.

Subsequent synchronous assemblage changes detected by K-means analysis across all biological groups post-1981 suggest a distinctive phase in the ecology of the ULE system. One possible explanation is the introduction of zebra mussels after the mid-1990s (Fig. 6b). Zebra mussels are well known to alter lake environments and food webs by reducing phytoplankton and hence grazer abundances and by stimulating macrophyte growth due to increases in water transparency (Higgins and Vander Zanden 2010). Our data provide little support for such zebra mussel effects, however. For example, grazer abundances (e.g. Daphnia spp.) increased during the same period, as did abundances of taxa tolerant of eutrophic conditions (e.g. the macrophytes L. trisulca, N. lutea, P. berchtoldii and P. pusillus) (Table 2). Similarly, ordination plots reveal convergence of macrophyte and chironomid assemblages to associations of eutrophication-tolerant taxa (Fig. 3). Glochidia larvae of Anodonta also increased during this time period. Anodonta competes directly with zebra mussels for food, and populations commonly diminish after the establishment of zebra mussels (Higgins and Vander Zanden 2010). Thus, all evidence points to negligible zebra mussel impacts in Castle Lough so far.

As a caveat, we note that constraints in palaeo-data and radiometric analyses should be considered when conducting plant macrofossil studies (Birks 2014). For example, some species (e.g. E. canadensis and $U$. vulgaris) are poorly preserved in sediments (Davis 1985; Davidson et al. 2005). However, surface sediment samples have also been shown to faithfully record the main spatial patterns in plant assemblages (Zhao et al. 2006; Clarke et al. 2014; Levi et al. 2014). Furthermore, the macrofossil record can over- or under-represent certain macrophyte taxa (Birks 2001; Davidson et al. 2005). For example, $C$. globularis, Nitella spp., and $N$. flexilis, produce large numbers of oospores/seeds, while Potamogeton species produce low numbers of seeds. Such disparity in propagule production can lead to misinterpretations of true plant 
500 abundances (Zhao et al. 2006). Our use of a semi-quantitative abundance scale (as in 501 Odgaard and Rasmussen 2001) for the plant macrofossil data helps to reduce such 502 effects. Moreover, similar to previous plant macrofossil studies in lakes (Davidson et 503 al. 2005; Zhao et al. 2006; Salgado et al. 2010; Clarke et al. 2014; Levi et al. 2014), 504 our palaeo-data capture most of the contemporary macrophyte community and 505 faithfully reflect current spatial distributions and differences between basin 1 and 506 basins 2 and 3 (Figs. 2a, 3, Table 2). Finally, our study is based on characterising 507 relative abundances over space and time within the same localities. Constraints 508 therefore are not expected to substantially influence our inferences.

509

Implications for long-term changes in ecological processes

510 Our data suggest a trend of spatial convergence of macrophytes and co-occurring

511 invertebrate communities post-1981 (Fig. 3, Table 2). This suggests that, as

512 eutrophication advances, the influence of water depth variation on assemblage

513 heterogeneity is gradually eroded, and that ultimately a limited set of eutrophication-

514 tolerant species will become homogeneously distributed across the entire lake.

515 Previous evidence for eutrophication effects on macrophytes includes reductions in 516 diversity and changes in seasonality (Ayres et al. 2008; Sayer et al. 2010a), which

517 ultimately result in loss of resilience (Sayer et al. 2010a,b). However, prior to our

518 study little was known regarding changes in macrophyte spatial distributions in 519 response to long-term nutrient-enrichment processes, nor of associated invertebrate 520 taxa. Our data revealed minimal macrophyte species turnover over time, but 521 substantial changes in macrophyte relative abundances across sites. This suggests that 522 reduced spatial variation in macrophyte and invertebrate relative abundances may 523 reflect an ecological phase that precedes major changes in species richness and 524 turnover (Arts 2002; Anderson et al. 2006). Such spatial homogenisation of relative 525 abundances may contribute to the loss of resilience associated with eutrophication 526 (Donohue et al. 2009) and warrants examination in future studies. 


\section{Conclusions}

529 Our study provides novel insights into how environmental influences have varied over 530 time to structure within-lake assemblages. We have analysed contemporary ecological 531 and palaeoecological data to collectively infer long-term changes in the pathways and 532 processes that underlie eutrophication effects in shallow lakes. The contemporary data

533 allow us to assess how macrophyte assemblages vary in composition and

534 heterogeneity according to basin-specific factors (e.g. variation in water depth). In

535 turn, the palaeoecological data enable us to infer basin-specific impacts of and

536 susceptibilities to eutrophication exhibited by macrophytes and invertebrates.

Our results indicate that variability in water depth promotes contemporary assemblage variation amongst Castle Lough's basins, thus stimulating within-lake macrophyte and invertebrate assemblage heterogeneity and thus higher lake biodiversity (Anderson et al. 2006). These insights are in keeping with growing evidence for the importance of spatial heterogeneity in structuring local populations and assemblages and the concomitant implications of scaling up from small-scale

543 studies (Ford et al. 2016). Our study also strongly suggests that eutrophication has

544 acted as a homogenising agent of macrophyte and co-occurring invertebrate

545 diversities and abundances over time at the whole-lake scale. Such homogenisation of 546 communities may have profound implications for shallow lake ecosystem functioning 547 including reductions in community resistance and resilience due to alterations in e.g. productivity and biomass production, variations in intra- and interspecific competition and increased vulnerability to species invasions (Hillebrand et al. 2008).

551 high variation in assemblages between basins and relatively high species richness.

552 Recently it has been inhabited by species regarded as sensitive to eutrophication and

553 rare in Northern Ireland (e.g. N. flexilis and broad-leaved Potamogeton taxa).

554 Unfortunately, hypertrophic states now characterise many water bodies of the ULE 555 system because of nutrient loading deriving from increasing dairy farming and urban 556 development (Gibson et al. 1995). If nutrient inputs continue, it is likely that Castle 
557 Lough will soon be characterised by spatially homogenous assemblages comprising a

558 few tolerant taxa and the conservation value of the lake will be greatly diminished.

559

\section{Acknowledgements}

560

561 We thank the Department of Zoology of The Natural History Museum, London for

562 funding this work as part of J. Salgado's PhD. A Hugh Cary Gilson Memorial Award

563 from the Freshwater Biological Association provided support for fieldwork. We also

564 thank the Departamento Administrativo de Ciencia, Tecnología e Innovación-

565 COLCINECIAS for supporting J. Salgado under the postdoctoral program "Es tiempo

566 de volver". T.A. Davidson's contribution was supported by CIRCE funding under the

567 AU ideas programme. We especially thank the Castle Lough landowners for site

568 access and hospitality, G. Simpson for statistical analysis advice, I. Jones and N.

569 Willby for constructive suggestions and P. Bexell and L. Petetti for fieldwork

570 assistance. We also thank the EU FP7 Project Biofresh (Biodiversity of Freshwater

571 Ecosystems: Status, Trends, Pressures, and Conservation Priorities) Contract No.

572226874 for financial support for sediment core dating analysis.

573

574

\section{References}

575

576 Aldridge DC, Horne DC (1998) Fossil glocchidia (Bivalvia, Unionidae):

577 identification and value in palaeoenvironmental reconstructions. J Micropalaeontol

578 17: 179-182

579

580 Allen MR, Vandyke JN, Caceres CE (2011) Metacommunity assembly and sorting in

581 newly formed lake communities. Ecology 92: 269-275

582

583 Anderson M (2001) A new method for non-parametric multivariate analysis of

584 variance. Austral Ecol 26: 32-46

585 
586 Anderson M (2006) Distance-based tests for homogeneity of multivariate dispersions.

589 Anderson M, Ellingsen K, McArdle B (2006) Multivariate dispersion as a measure of 590 beta diversity. Ecol Lett 9: 683-693

Appleby PG, Nolan PJ, Gifford DW, Godfrey MJ, Oldfield F, Anderson NJ, Battarbee RW (1986) ${ }^{210} \mathrm{~Pb}$ dating by low background gamma counting. Hydrobiologia 141: 21-27

595

Appleby PG, Oldfield F (1978) The calculation of lead-210 dates assuming a constant rate of supply of unsupported ${ }^{210} \mathrm{~Pb}$ to the sediment. Catena 5: 1-8

Arts GH (2002) Deterioration of Atlantic soft water macrophyte communities by 601 acidification, eutrophication and alkalinisation. Aquat Bot 31: 373-93

608

609 Barrat-Segretain, M. H. (1996). Strategies of reproduction, dispersion, and competition in river plants: a review. Vegetatio 123: 13-37

611

612 Battarbee R (1986) The Eutrophication of Lough Erne inferred from changes in the 613 diatom assemblages of ${ }^{210} \mathrm{~Pb}$ - and ${ }^{37} \mathrm{Cs}$ dated sediment cores. Proc $\mathrm{R}$ Ir Acad 86B: $614 \quad 141-168$ 615 616 Birks HJ (2014) Challenges in the presentation and analysis of plant-macrofossil 
618

619 Birks HH (2001) Plant macrofossils. In: Smol JP, Birks HJB, Lasts WM (ed)

620 Tracking environmental change using lake sediments, vol 3: terrestrial, algal and

621 siliceous indicators. Kluwer, Dordecht, pp 49-74

622

623

624

625

626

627

628 629

630

631 632 633

634 635 636 637 640

645 Cummins RH (1994) Taphonomic processes in modern freshwater molluscan death 646 assemblages: implications for the freshwater fossil record. Palaeogeogr

647 Palaeoclimatol Palaeoecol 108: 55-73

Brodersen KP, Odgaard BV, Vestergaard O, Anderson N J (2001) Chironomid stratigraphy in the shallow and eutrophic Lake Søbygaard, Denmark: chironomidmacrophyte co-occurrence. Freshw Biol 46: 253-267

Brodersen K, Lindegaard C (1999) Classification, assessment and trophic reconstruction of Danish lakes using chironomids. Freshw Biol 42: 143-157

Brooks SJ, Heiri O, Langdon PG (2007) The identification and use of palaearctic chironomidae larvae in palaeoecology. Technical guide No. 10. Quaternary Research Association, London

Canfield DEJr, Shireman J, Colle DE, Haller WT, Watkins CEII, Maceina MJ (1984)

Prediction of chlorophyll $a$ concentrations in Florida lakes: importance of aquatic macrophytes. Can J Fish Aquat Sci 41: 497-501

Carpenter S, Titus JE (1984) Composition and spatial heterogeneity of submersed vegetation in a softwater lake in Wisconsin. Plant Ecol 57: 153-165

Clarke GH, Sayer CD, Turner S, Salgado J, Meis S, Patmore IR Zhao Y (2014) Representation of aquatic vegetation change by plant macrofossils in a small and shallow freshwater lake. Veg Hist Archaeobot 23: 265-276 
649 Davidson TA, Sayer CD, Langdon PG, Burgess A, Jackson M (2010) Inferring past 650 zooplanktivorous fish and macrophyte density in a shallow lake: application of a new 651 regression tree model. Freshw Bio 55: 584-599

652

653 Davidson TA, Sayer CD, Bennion H, David C, Rose N, Wade M (2005) A 250 year

654 comparison of historical, macrofossil and pollen records of aquatic plants in a shallow 655 lake. Freshw Biol 50: 1671-1686

656

Davis FW (1985) Historical changes in submerged macrophyte communities of upper 658 Chesapeake Bay. Ecology 66: 981-993

659

660 Donohue I, Jackson AL, Pusch MT, Irvine K (2009) Nutrient-enrichment

661 homogenizes lake benthic assemblages at local and regional scales. Ecology 90: 3470$662 \quad 3477$

663

664 Dufrene M, Legendre P (1997) Species assemblages and indicator species: the need 665 for a flexible asymmetrical approach. Ecol Monogr 67: 345-366

666

667 Faith DP, Minchin PR, Belbin L (1987) Compositional dissimilarity as a robust 668 measure of ecological distance. Vegetatio 69: 57-68

669

670 Ford JR, Shima JS, Swearer SE (2016) Interactive effects of shelter and conspecific

671 density shape mortality, growth, and condition in juvenile reef fish. Ecology 97:

$672 \quad 1373-80$

673

674 Fukami T, Morin P (2003) Productivity-biodiversity relationships depend on the 675 history of community assembly. Nature 424: 423-426

676

677 Gibson C, Wu Y, Smith S, Wolfe-Murphy S (1995) Synoptic limnology of a diverse 678 geological region: catchment and water chemistry. Hydrobiologia 306: 213-227 679 680 Hartikainen H, Johnes P, Moncrieff C, Okamura B (2009) Bryozoan populations 
681 reflect nutrient-enrichment and productivity gradients in rivers. Freshw Biol 54: 2320-

682 2334

683

684

685

686

687

688

689

690

691

692

693

694

695

696

697

698

699

700

701

702

703

704

705

706

707

708

709

710

71

712

Higgins SN, Vander Zanden MJ (2010) What a difference a species makes: a metaanalysis of dreissenid mussel impacts on freshwater ecosystems. Ecol Monogr 80: $179-196$

Hillebrand H, Bennett DM, Cadotte MW (2008) Consequences of dominance: a review of evenness effects on local and regional ecosystem processes. Ecology 89: $1510-1520$

Jeppesen E, Sondergaard M, Sondergaard M, Christofferson K, editors (2012) The structuring role of submerged macrophytes in lakes. Springer Science \& Business Media, Netherlands.

Keddy PA, Reznicek AA (1986) Great Lakes vegetation dynamics: the role of fluctuating water levels and buried seeds. J GT Lakes Res 12: 25-36

Korhonen JJ, Soininen J, Hillebrand H (2010) A quantitative analysis of temporal turnover in aquatic species assemblages across ecosystems. Ecology 91: 508-517

Langdon PG, Ruiz Z, Wynne S, Sayer CD, Davidson TA (2010) Ecological influences on larval chironomid communities in shallow lakes: implications for palaeolimnological interpretations. Freshw Biol 55: 531-545

Lauridsen T, Pedersen L J, Jeppesen E, Sønergaard M (1996) The importance of macrophyte bed size for cladoceran composition and horizontal migration in a shallow lake. J Plankton Res 18: 2283-2294

Lauridsen T, Lodge D (1996) Avoidance by Daphnia magna of fish and macrophytes: chemical cues and predator-mediated use of macrophyte habitat. Limnol Oceanogr 41: 794-798 
714 Legendre P, Cáceres MD, Borcard D (2010) Community surveys through space and

715 time: testing the space-time interaction in the absence of replication. Ecology 91: 262-

$716 \quad 272$

717

718 Leibold M, Holyoak M, Mouquet N, Amarasekare P, Chase J, Hoopes M, Holt R, 719 Shurin J, Law R, Tilman D (2004) The metacommunity concept: a framework for 720 multi-scale community ecology. Ecol Lett 7: 601-613

721

722 Leibold M, Norberg J (2004) Biodiversity in metacommunities: Plankton as complex

723 adaptive systems? Limnol Oceanogr 49: 1278-1289

Levi EE, Çakıroğlu Aİ, Bucak T, Odgaard B-V, Davidson TA, Jeppesen E,Beklioğlu

M (2014) Similarity between contemporary vegetation and plant remains in the sediment surface in Mediterranean lakes. Freshw Biol 59: 724-736

728

Madgwick G, Emson D, Sayer CD, Willby N, Rose NL, Jackson MJ, Kelly A (2011)

730 Centennial-scale changes to the aquatic vegetation structure of a shallow eutrophic

731 lake and implications for restoration. Freshw Biol 56: 2620-36

Mathers R, De Carlos M, Crowley K, Teangana DÓ (2002) A review of the potential

734 effect of Irish hydroelectric installations on Atlantic salmon (Salmo salar L.)

735 populations, with Particular Reference to the River Erne. Proc R Ir Acad 102B: 69-79 736

737 Moller Pillot HKM (2009) Chironomidae Larvae: Biology and ecology of the

738 Chironomini. KNNV Publishing, Zeist, The Netherlands

739

740 Moller Pillot HKM (2013) Chironomidae Larvae: Biology and ecology of the aquatic

741 Orthocladiinae. KNNV Publishing, Zeist, The Netherlands

742

743 Økland KA, Økland J (2002) Freshwater bryozoans (Bryozoa) of Norway III:

744 distribution and ecology of Plumatella fruticosa. Hydrobiologia 479: 11-22 
746 Odgaard B, Rasmussen P (2001) The occurrence of egg-cocoons of the leech

747 Piscicola geometra (L.) in recent sediments and their relationship with the remains of

748 submerged macrophytes. Arch Hydrobiol 52: 671-686

750 Peres-Neto PR, Legendre P, Dray S, Borcard D (2006) Variation partitioning of

751 species data matrices: estimation and comparison of fractions. Ecology 87: 2614-2625

752

753 Pinder LCV, Reiss F (1983) The larvae of Chironominae (Diptera: Chironomidae) of 754 the Holartic region. Keys and diagnoses. Entomol Scand Suppl 19: 293-435 755

Price J (1890) Lough Erne Drainage. P I Civil Eng C1: 73-94

757

758

R Core Development Team. (2009) R 2.9.2. R project for Statistical Computing.

759

Vienna, Austria. www.r-project.com

760

761

Rasmussen P, Anderson NJ (2005) Natural and anthropogenic forcing of aquatic

762 macrophyte development in a shallow Danish lake during the last 7000 years. J Biogeogr 32: 1993-2005

764

765

Riis T, Sand-Jensen K, Larsen SE (2001) Plant distribution and abundance in relation to physical conditions and location within Danish stream systems. Hydrobiologia 448: 217-228

768

769

770

Rosell RS, Maguire CM, McCarthy TK (1998) First reported settlement of zebra 
777 Sand-Jensen K, Pedersen NL, Thorsgaard I, Moeslund B, Borum J, Brodersen KP 800 807 808 (2008) 100 years of vegetation decline and recovery in Lake Fure, Denmark. J Ecology 96: 260-271

Sayer CD, Davidson TA, Jones, JI (2010a) Seasonal dynamics of macrophytes and phytoplankton in shallow lakes: a eutrophication-driven pathway from plants to plankton? Freshw Biol 55: 500-513

\section{Sayer CD, Burgess AM, Kari K, Davidson TA, Peglar S, Yang H, Rose N (2010b)}

Long-term dynamics of submerged macrophytes and algae in a small and shallow, eutrophic lake: implications for the stability of macrophyte-dominance. Freshw Biol 55: $565-83$

Sculthorpe CD (1967) The biology of aquatic plants. Edward Arnold Ltd., London. Smolders A, Lamers L, Hartog C,Roelofs J (2003) Mechanisms involved in the decline of Stratiotes aloides L. in the Netherlands: sulphate as a key variable. Hydrobiologia 506: 603-610

Spence DHN, Chrystal J (1970) Photosynthesis and zonation of freshwater macrophytes. New Phytol 69: 217-227

Spence, D. (1967) Factors controlling the distribution of freshwater macrophytes with particular reference to the lochs of Scotland. J Ecol 55: 147-170

Urban MC, De Meester L (2009) Community monopolization: local adaptation enhances priority effects in an evolving metacommunity. Proc R Soc Biol Sci Ser B 276: 4129-4138

\section{Vallenduuk HJ, Moller Pillot HKM (2007) Chironomidae Larvae: General ecology} and Tanypodinae. KNNV Publishing, Zeist, The Netherlands

Wood TS, Okamura B (2005) A new key to the freshwater bryozoans of Britain, 
809 Ireland and continental Europe, with notes on their ecology. The Freshwater

810 Biological Association, Ambleside

811

812 Zhao Y, Sayer CD, Birks HH, Hughes M, Peglar S (2006). Spatial representation of

813 aquatic vegetation by macrofossils and pollen in a small and shallow lake. $\mathbf{J}$

814 Paleolimnol 35: 335-350 


\section{Tables}

815 Table 1. Effects of space, time and their interaction (S-T) on the abundances of

816 macrophytes, chironomids, molluscs, bryozoans and daphnid in three sediment cores

817 form Castle Lough. * $P \leq 0.05$; ** $P \leq 0.01$; *** $P \leq 0.001$

\begin{tabular}{cccccccccc}
\hline & S-T & Space & Time \\
\hline
\end{tabular}

$\begin{array}{lllllllll}\text { Macrophytes } \quad 2.8461 & 0.2722 & 0.001 * * * & 5.1164 & 0.1957 & 0.001 * * * & 1.2815 & 0.2451 & 0.173\end{array}$

$\begin{array}{llllllllll}\text { Chironomids } & 2.6839 & 0.3153 & 0.001 * * * & 1.8326 & 0.0861 & 0.027 * & 1.0476 & 0.2461 & 0.599\end{array}$

$\begin{array}{llllllllll}\text { Molluscs } & 2.2703 & 0.2863 & 0.02 * * & 1.4394 & 0.0726 & 0,256 & 1.0414 & 0.2627 & 0.513\end{array}$

$\begin{array}{llllllllll}\text { Bryozoans } & 1.6363 & 0.0994 & 0,18 & 2.6353 & 0.6402 & 0.001 * * * & 0.6435 & 0.0782 & 0.825\end{array}$

$\begin{array}{llllllllll}\text { Daphnids } & 0.1188 & 0.0187 & 0,989 & 6.6253 & 0.4165 & 0.01 * * & 0.2969 & 0.0933 & 0.987\end{array}$

818

819 
Table 2. Summary of selected characteristic macrophyte, chironomid, mollusc, bryozoan and daphnid species identified by the greatest

Species

$\underline{\text { Ecology }}$

Pre-1900-193

12

$\underline{1931-1980}$

Macrophytes

Najas flexilis

Oligo-mesotrophic

Bryophytes

Oligo-mesotrophic

Nitella spp.

Isoetes lacustris

Stratiotes aloides

Potamogeton obtusifolius/friesii

Myriophyllum spp.

Oligo-mesotrophic

Oligo-mesotrophic

Meso-eutrophic

Meso-eutrophic

Potamogeton praelongus/lucens

Littoral; meso-eutrophic

Nymphaea alba

Profundal-mesotrophic

Nymphaeaceae (N. lutea/N.

alba)

Lemna trisulca

Meso-eutrophic

Meso-eutrophic

Meso-eutrophic

Sparganium sp.

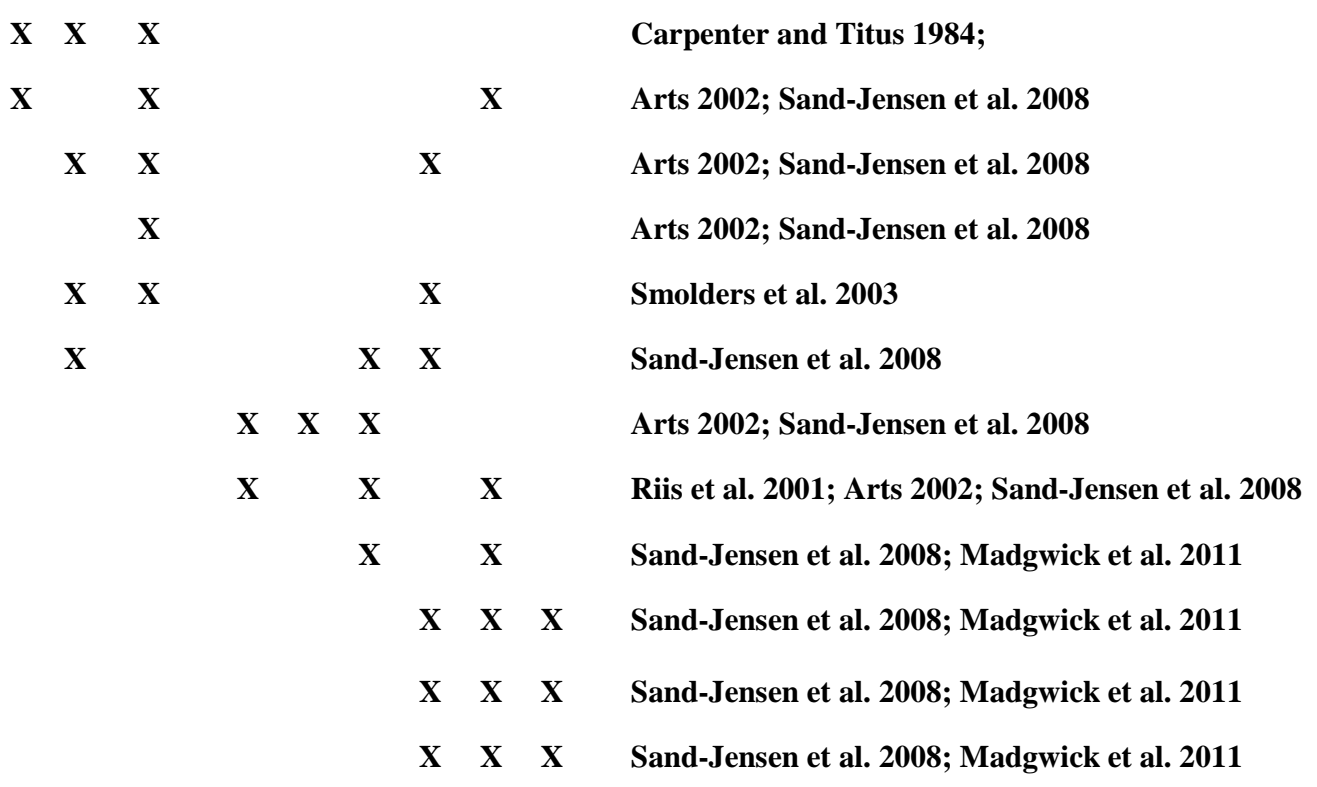


Chara globularis

Chironomids

Chironomus anthracinus

$\mathbf{X}$

Chironomus plumosu

Orthocladius consobrinus

Protanypus

Cladopelma lacophila

Stempellina

Pseudochironomus

Microtendipes pedellus

Tanytarsus lugens

Tanytarsus pallidicornis

Cladotanytarsus mancus

Ablabesmyia

Tanytarsus mendax

Dicrotendipes nervosus

Glyptotendipes pallens

Psetroclaudius/Cricotopus agg.

Stenochironomus
Profundal; eutrophic

Meso-eutrophic

Profundal; eutrophic

Oligotrophic

Profundal; oligo-mesotrophic

Littoral; oligo-mesotrophic

Oligotrophic

Littoral ;oligo-mesotrophic

Littoral; mesotrophic

Profundal; mesotrophic

Littoral; meso-eutrophic

Littoral; meso-eutrophic

$+\mathrm{V}$

Littoral; meso-eutrophic

Littoral; meso-eutrophic; +V

Littoral; meso-eutrophic; +V

Littoral; meso-eutrophic; +V

Littoral; meso-eutrophic; +V
X X X $\quad$ Madgwick et al. 2011

X X Pinder and Reiss 1983; Brodersen and Lindegaard 1999; Moller Pillot 2009

Pinder and Reiss 1983; Brodersen and Lindegaard 1999; Moller Pillot 2009

X Pinder and Reiss 1983; Brodersen and Lindegaard 1996; Moller Pillot 2013

Pinder and Reiss 1983; Brodersen and Lindegaard 1999

X Brooks et al. 2007; Moller Pillot 2009

Brooks et al. 2007; Vallenduuk and Moller Pillot 2007

Brooks et al. 2007; Vallenduuk and Moller Pillot 2007

Moller Pillot 2009; Moller Pillot 2009

$\mathbf{x}$

X X Brooks et al. 2007; Vallenduuk and Moller Pillot 2007

$\mathbf{X} \mathbf{X}$

$\mathbf{X} \mathbf{X}$

$\mathbf{X} \mathbf{X}$

$\mathbf{X} \mathbf{X}$

$\mathbf{X} \mathbf{X}$

$\mathbf{X}$

$\begin{array}{lll}\mathbf{X} & \mathbf{X}\end{array}$

$\mathbf{X} \quad \mathbf{X} \quad \mathbf{X}$

$\mathbf{X}$
Brooks et al. 2007; Vallenduuk and Moller Pillot 2007

Brooks et al. 2007; Vallenduuk and Moller Pillot 2007

Brooks et al. 2007

Brooks et al. 2007; Vallenduuk and Moller Pillot 2007

Brooks et al. 2007; Moller Pillot 2009

Brooks et al. 2007; Moller Pillot 2009; Langdon et al. 2010

Brodersen et al. 2001; Moller Pillot 2013

X Brodersen et al. 2001; Vallenduuk and Moller Pillot 2007 


\author{
Glyptotendipes barbibes \\ Littoral; meso-eutrophic; +V \\ Endochironomus albipennis \\ Polypedilum nubeculosum \\ Procladius \\ Microchironomus \\ Littoral; meso-eutrophic; +V \\ Littoral; meso-eutrophic; $+\mathrm{V}$ \\ Profundal; meso-eutrophic \\ Profundal; meso-eutrophic
}

\section{$\underline{\text { Invertebrates }}$}

Plumatella fruticosa

Daphnia spp.

Ceriodaphnia spp.

Cristatella mucedo

Plumatella spp.

Pisidium spp.

Dreissena polymorpha

Gastropoda

Glochidia larvae

\section{Oligo-mesotrophic}

Profundal \& shallow; -V/+V

Shallow; +V

Meso-eutrophic

Eutrophic

$+\mathrm{V}$

Littoral \& profundal; +V

$+\mathrm{V}$

Fish parasites; $+\mathbf{V}$
X $\quad \mathbf{X}$

Brodersen et al. 2001; Langdon et al. 2010; Moller Pillot 2009

X X X Brodersen et al. 2001; Moller Pillot 2009

$X \quad X \quad X \quad$ Moller Pillot 2009; Langdon et al. 2010

$\begin{array}{llll}X & X & X & \text { Brooks et al. } 2007\end{array}$

X $\quad$ X $\quad$ Brooks et al. 2007; Moller Pillot 2009

$\begin{array}{lll}\mathbf{X} & \mathbf{X} & \mathbf{X} \\ \mathbf{X} & & \\ \mathbf{X} & & \mathbf{X}\end{array}$

$\mathbf{X}$

$X \quad X \quad$ Lauridsen and Lodge 1996; Lauridsen et al. 1996

$X \quad$ Lauridsen and Lodge 1996; Lauridsen et al. 1996

X X X $\quad$ Økland and Økland 2002

X X Økland and Økland 2002; Hartikainen et al. 2009

$\begin{array}{llll}\text { X } & X & X & \text { Jepessen et al. } 2012\end{array}$

$\begin{array}{llll}X & X & \text { Higgins and Vander Zanden } 2010\end{array}$

X $\quad$ X $\quad$ X Jepessen et al. 2012

$\begin{array}{llll}X & X & X & \text { Cummins } 1994\end{array}$ 


\section{Figure legends}

826 Figure 1. (a) Castle Lough location; (b) Details of surrounding environment, 827 hydrological connectivity, bathymetry and sampling areas. Open circles represent 828 contemporary macrophyte sampling areas in each lake basin. Black circles indicate 829 locations of cores NCAS1, NCAS2 and NCAS3 within each basin.

830

831 Figure 2. (a) Box plots presenting the macrophyte percentage frequencies in each 832 basin; (b) Negative binomial generalized linear model (GLM) for total macrophyte 833 percentage frequency and water depth values at each sampling point across the three 834 study basins. $\mathrm{AIC}=1579 ; \mathrm{P}=2 \mathrm{e}-16^{* * *} ;{ }_{\text {adj }} \mathrm{R}^{2}=30.4 \%$.

835

Figure 3. Plots of Non-Metric Multidimensional Scale (NMDS) analyses for: (a)

837 Contemporary macrophytes; (b) Plant-macrofossils; (c) chironomids; (s) Molluscs; (e) 838 Bryozoans; (f) Daphnids. $1=$ basin $1 ; 2=$ basin $2 ; 3=$ basin $3 . \mathrm{H}=$ historical times $c$. pre-1900; $\mathrm{P}=$ contemporary data (present-day)

841 Figure 4. Plant-macrofossil stratigraphy for cores NCAS1- basin 1 (black), NCAS2842 basin 2 (dark grey), and NCAS3- basin 3 (light grey). Dotted lines represent a c. 10843 year time-period. Solid black lines represent the zones determined by K-means 844 analysis, corresponding to $c$. pre-1900-1920, 1931-1980 and 1981-present.

846 Figure 5. Representative chironomid-macrofossil stratigraphy for cores NCAS1847 basin 1 (black), NCAS2- basin 2 (dark grey), and NCAS3- basin 3 (light grey). Dotted 848 lines represent a $c$. 10-year time-period. Solid black lines represent the zones 849 determined by K-means analysis, corresponding to $c$. pre-1900-1920, 1921-1940, 850 1941-1955, 1956-1980 and 1981-present. 
851 Figure 6. (a) Mollusc; (b) Bryozoan; and (c) Daphnid macrofossil stratigraphies for

\section{Electronic supplemental material (ESM)}

Figure ESM4. Spatiotemporal maps showing K-means partition of (a) Plant

871 assemblages in the cores NCAS1, NCAS2 and NCAS3. Simple structure index (ssi) is

872 indicated on the right-hand side of each map. Selected number of groups by ssi is

873 indicated with a bold black circle. 


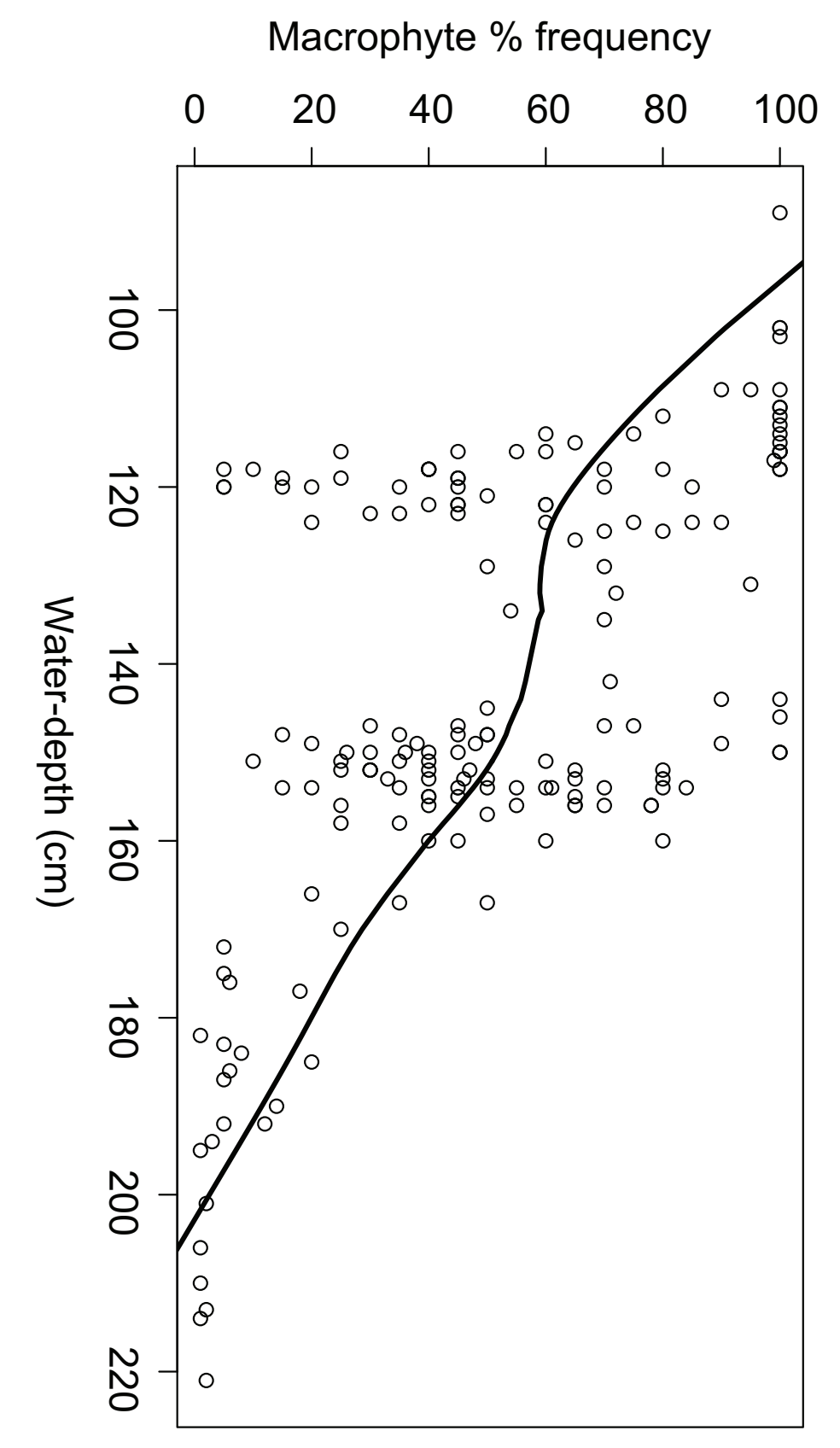

$\sigma$

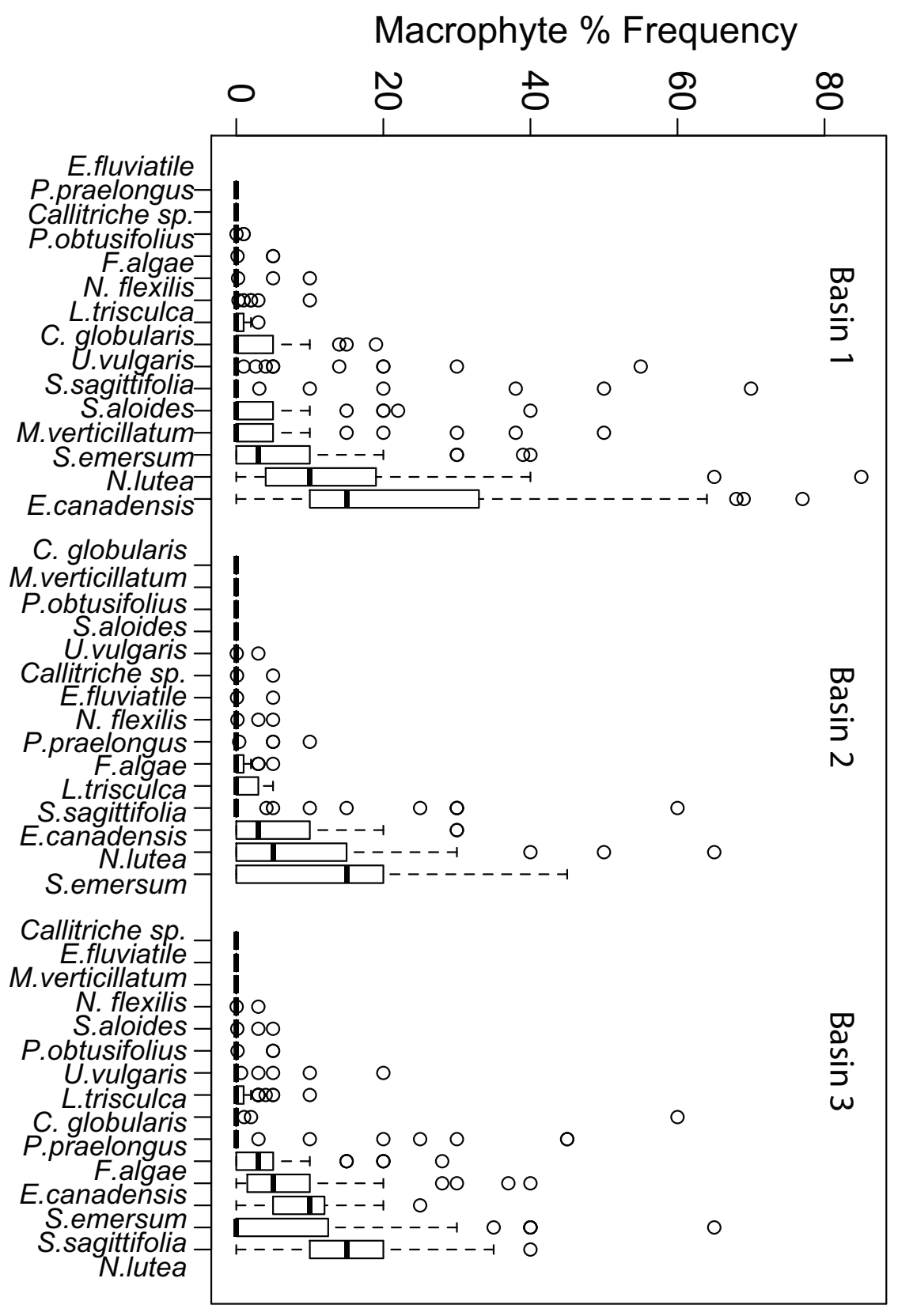

อง 


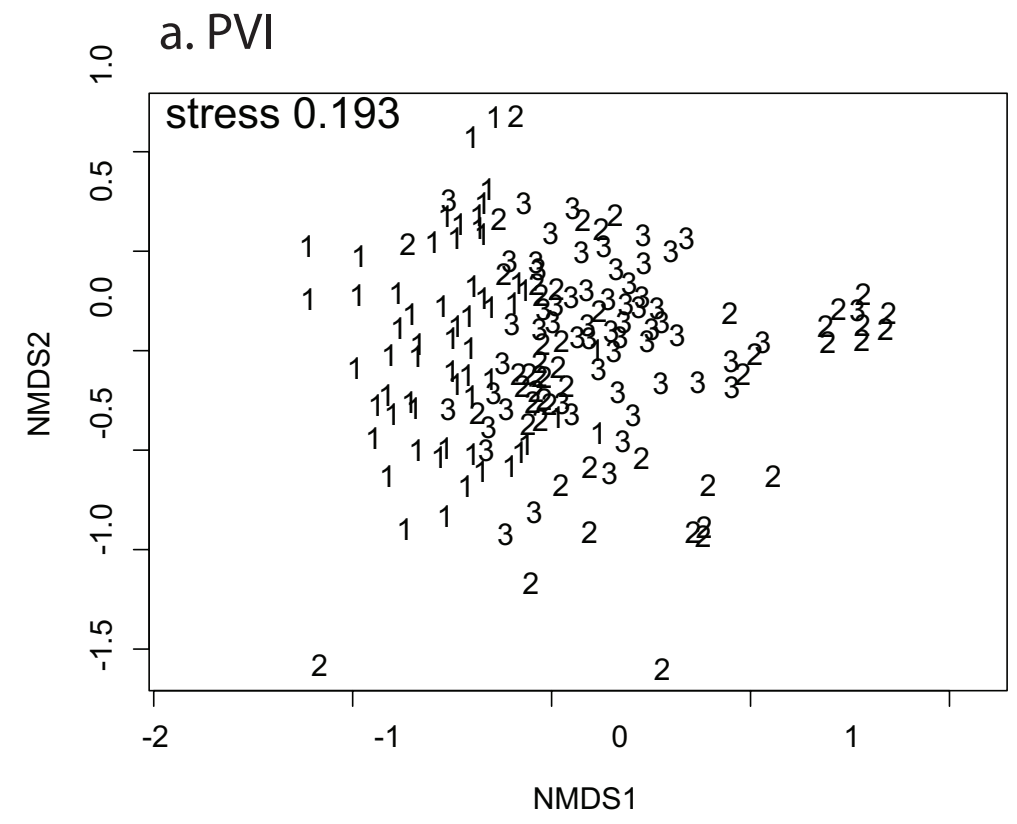

\section{$\therefore$ b. Plant macrofossils}

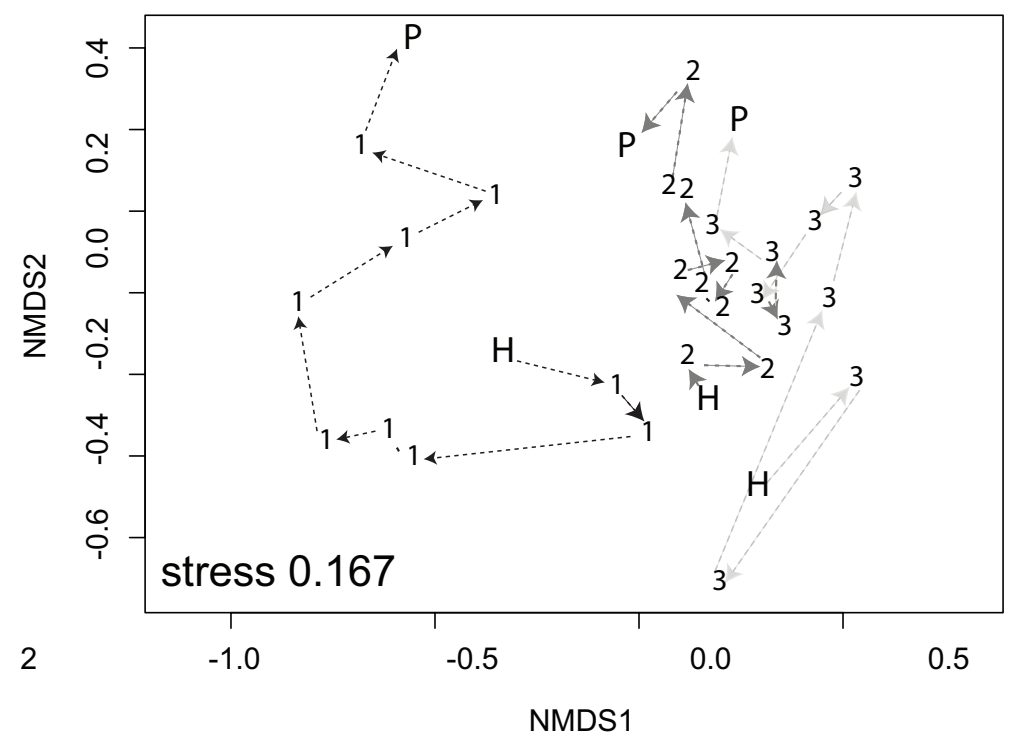

\section{c. Chironomids}

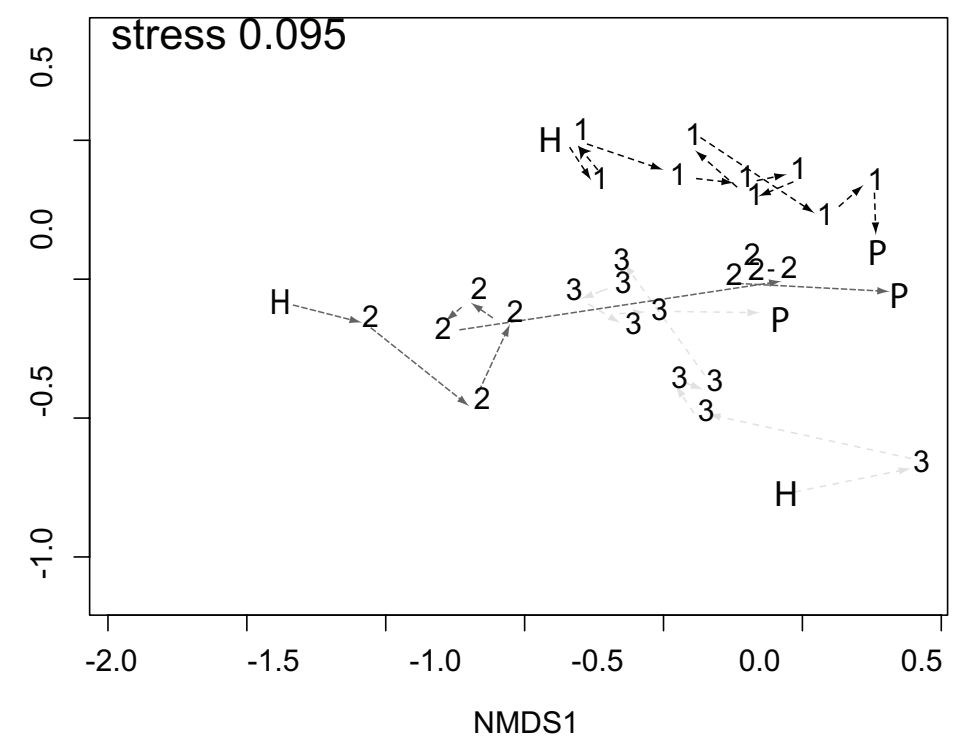

\section{$\stackrel{\circ}{-}$ e. Bryozoans}

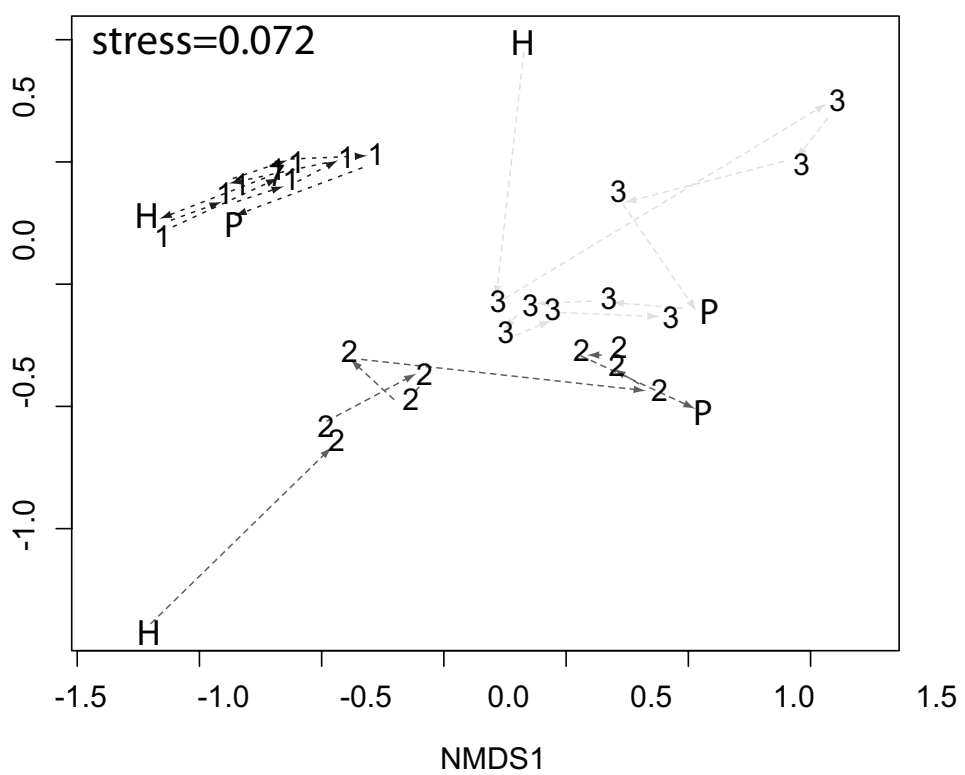

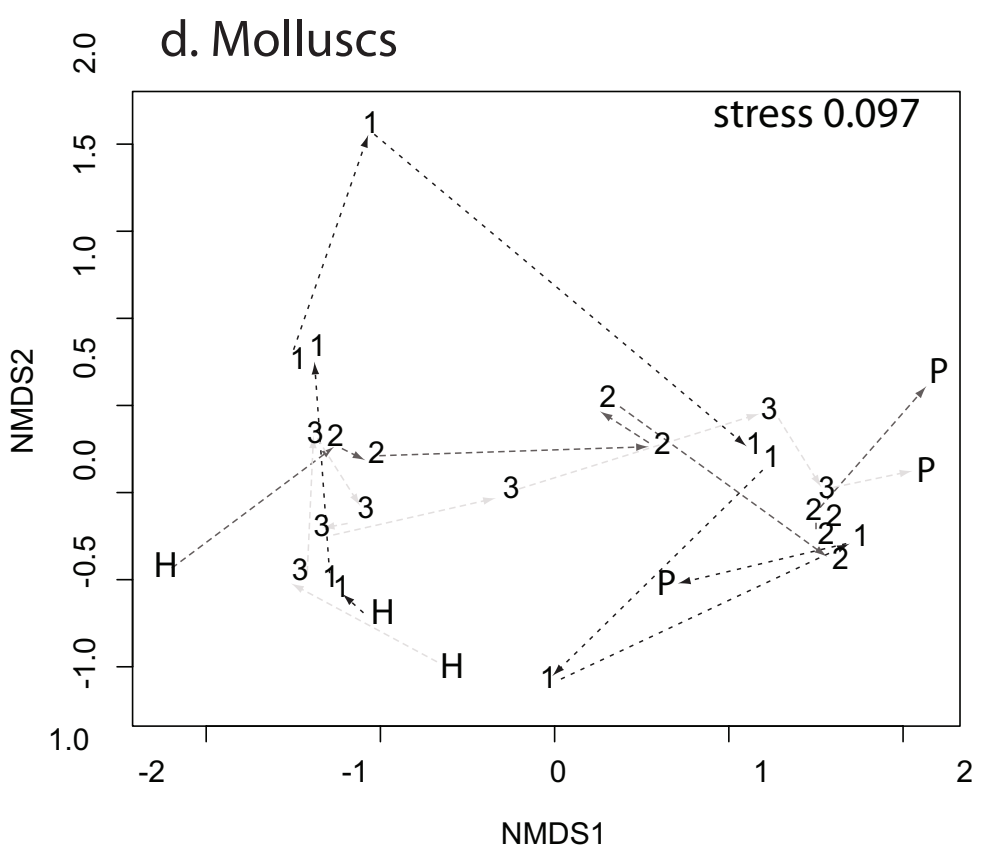

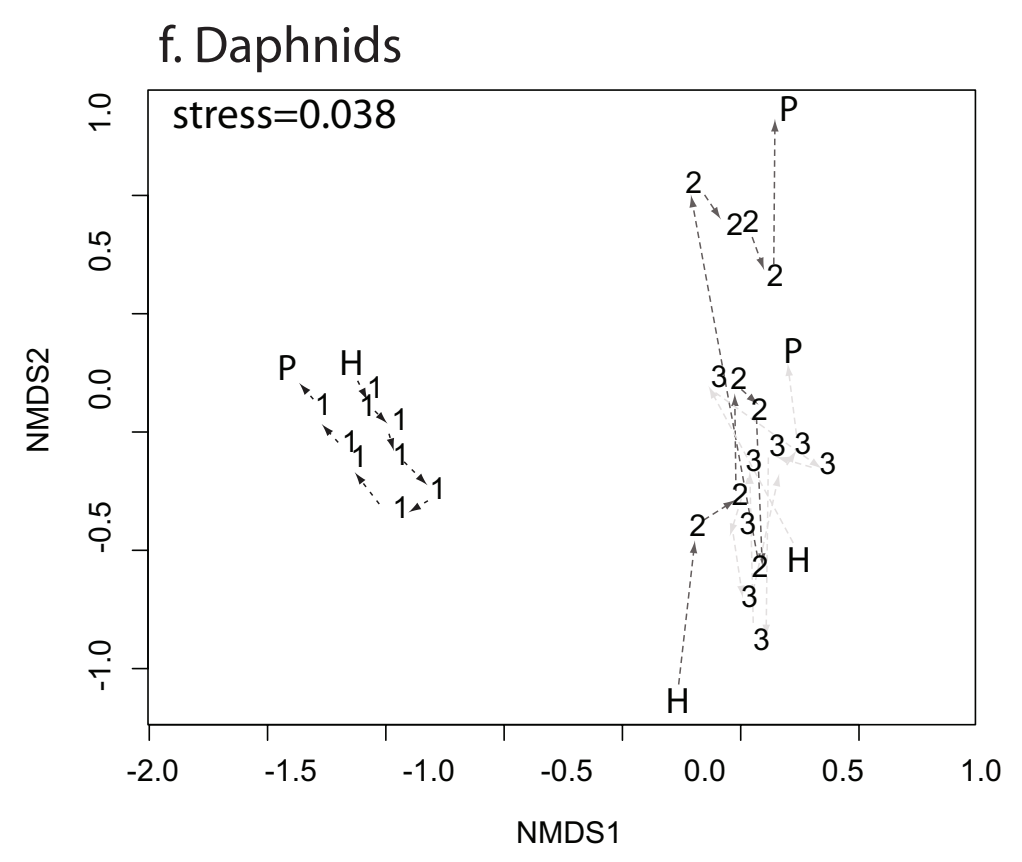



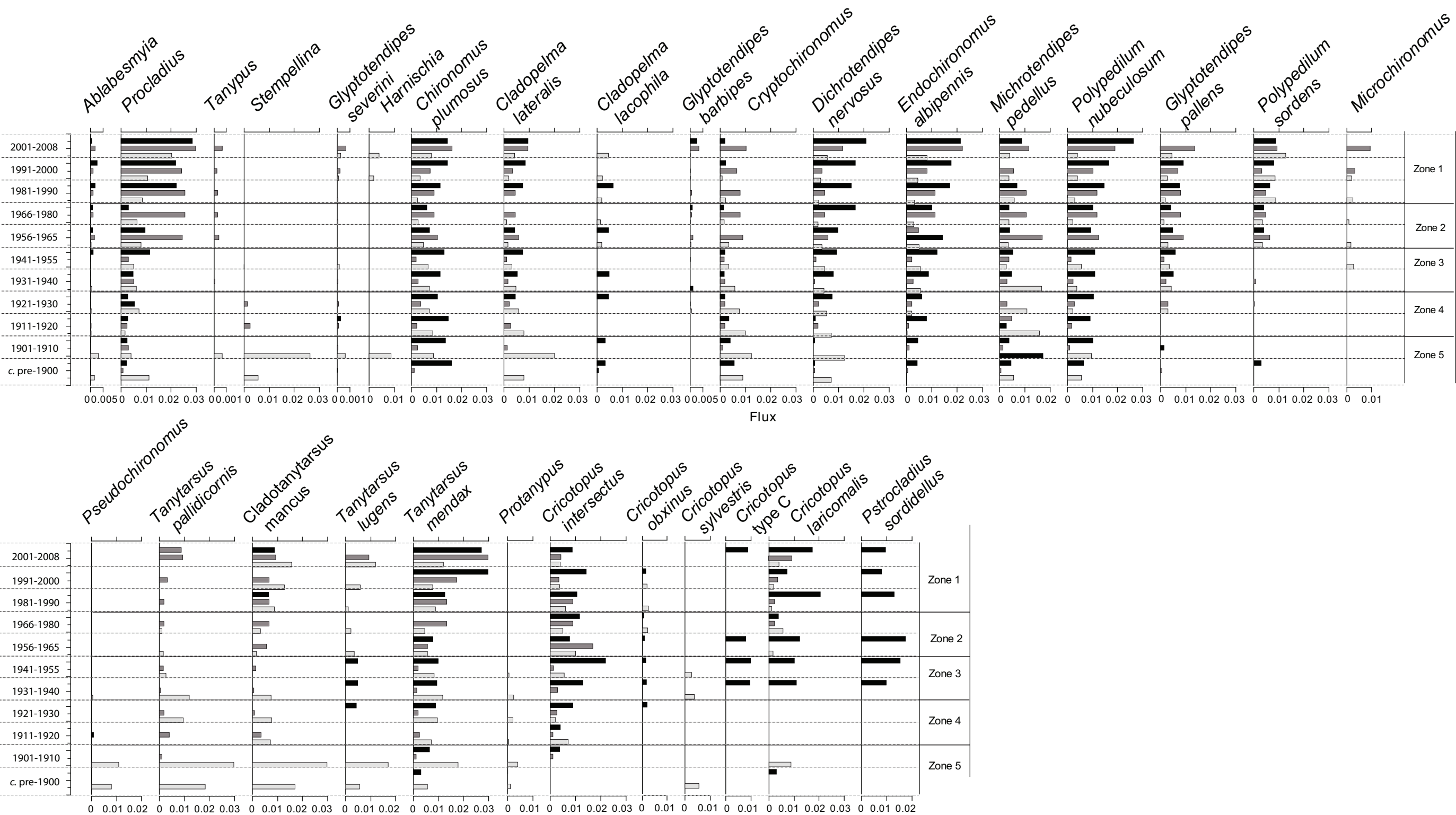

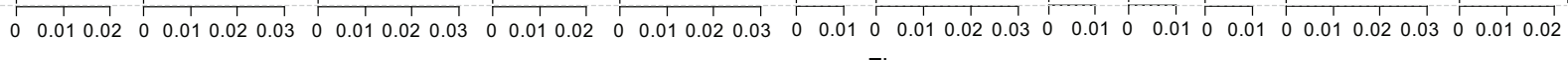


Click here to view linked References

1

2

3

4

5

6

8

9

10

11

12

13

16 a. NCAS1 b. NCAS2

17

Age (yr)

Age (yr)

80

120

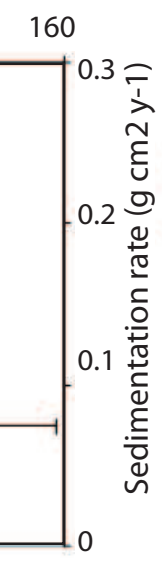

c. NCAS3

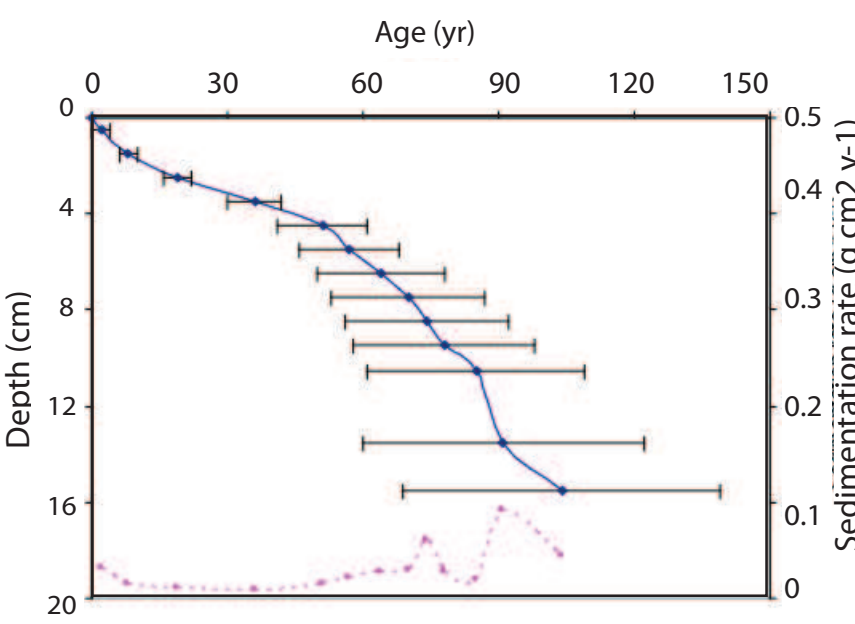


3

4

5

6

8

9

10

11

12

13

14

15
16

1

a. Chara globularis

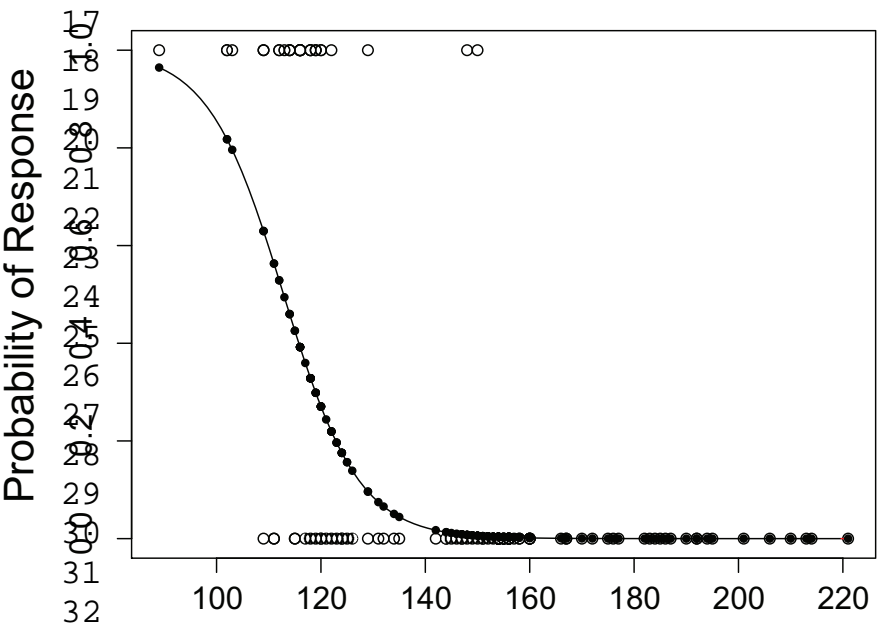

b. Myriopyllum verticillatum

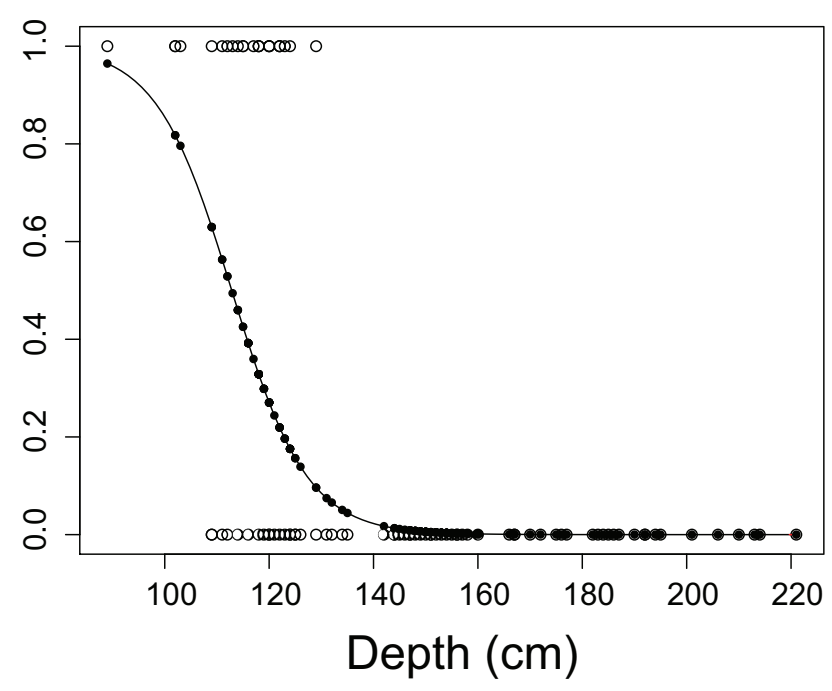

c. Stratiotes aloides

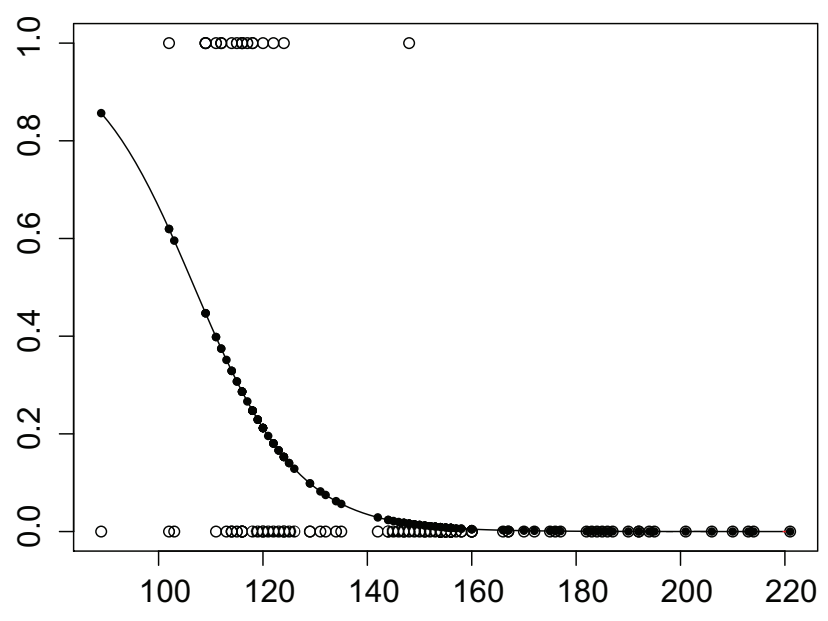


